\title{
Discharge Profiles across the Sleep-Waking Cycle of Identified Cholinergic, GABAergic, and Glutamatergic Neurons in the Pontomesencephalic Tegmentum of the Rat
}

\author{
Soufiane Boucetta, ${ }^{1}$ Youssouf Cissé, ${ }^{1}$ Lynda Mainville, ${ }^{1}$ Marisela Morales, ${ }^{2}$ and Barbara E. Jones ${ }^{1}$ \\ ${ }^{1}$ Department of Neurology and Neurosurgery, Montreal Neurological Institute, McGill University, Montreal, Quebec H3A 2B4, Canada, and ${ }^{2}$ National \\ Institute on Drug Abuse, Neuronal Networks Section, National Institutes of Health, Baltimore, Maryland 21224
}

Distributed within the laterodorsal tegmental and pedunculopontine tegmental nuclei (LDT and PPT), cholinergic neurons in the pontomesencephalic tegmentum have long been thought to play a critical role in stimulating cortical activation during waking (W) and paradoxical sleep (PS, also called REM sleep), yet also in promoting PS with muscle atonia. However, the discharge profile and thus precise roles of the cholinergic neurons have remained uncertain because they lie intermingled with GABAergic and glutamatergic neurons, which might also assume these roles. By applying juxtacellular recording and labeling in naturally sleeping-waking, head-fixed rats, we investigated the discharge profiles of histochemically identified cholinergic, GABAergic, and glutamatergic neurons in the LDT, SubLDT, and adjoining medial part of the PPT (MPPT) in relation to sleep-wake states, cortical activity, and muscle tone. We found that all cholinergic neurons were maximally active during $\mathrm{W}$ and PS in positive correlation with fast $(\gamma)$ cortical activity, as "W/PS-max active neurons." Like cholinergic neurons, many GABAergic and glutamatergic neurons were also "W/PS-max active." Other GABAergic and glutamatergic neurons were "PS-max active," being minimally active during W and maximally active during PS in negative correlation with muscle tone. Conversely, some glutamatergic neurons were "W-max active," being maximally active during W and minimally active during PS in positive correlation with muscle tone. Through different discharge profiles, the cholinergic, GABAergic, and glutamatergic neurons of the LDT, SubLDT, and MPPT thus appear to play distinct roles in promoting W and PS with cortical activation, PS with muscle atonia, or $\mathrm{W}$ with muscle tone.

Key words: EEG; EMG; paradoxical sleep; REM sleep; slow-wave sleep

\section{Introduction}

Many pharmacological and neurophysiological studies have indicated the importance of acetylcholine (ACh) and the AChcontaining neurons in the pontomesencephalic tegmentum in stimulating cortical activation, which occurs during waking (W) and paradoxical sleep (PS or REM sleep), yet also in promoting PS with muscle atonia (Jones, 1993; Steriade, 2004). The cholinergic pontomesencephalic neurons are located in the laterodorsal and pedunculopontine tegmental nuclei (LDT and PPT) and give rise to ascending projections into the forebrain and local projections into the brainstem reticular formation (RF), by which they can influence cortical activity, muscle tone, and sleep-wake states (Paré et al., 1988; Jones, 1990; Semba et al., 1990; Jones, 1993).

\footnotetext{
Received June 19, 2013; revised Feb. 19, 2014; accepted Feb. 22, 2014.

Author contributions: B.E.J. designed research; S.B., Y.C., L.M., and M.M. performed research; S.B. and B.E.J. analyzed data; S.B. and B.E.J. wrote the paper.

This work was supported by the Canadian Institutes of Health Research Grant CIHR MOP-13458 to B.E.J., the National Institutes of Health Grant NIH R01 MH-60119-01A to B.E.J., and the Intramural Research Program of the National Institute on Drug Abuse to M.M. We thank Oum Kaltoum Hassani (Montreal) for assistance with electrophysiological recordings and advice and Liu Bing (Baltimore) for assistance with histochemical processing.

The authors declare no competing financial interests.

Correspondence should be addressed to Dr. Barbara E. Jones, Montreal Neurological Institute, McGill University, 3801 University Street, Montreal, Quebec, Canada H3A 2B4. E-mail: barbara.jones@mcgill.ca.

DOI:10.1523/JNEUROSCI.2617-13.2014

Copyright $\odot 2014$ the authors $\quad 0270-6474 / 14 / 344708-20 \$ 15.00 / 0$
}

Although minimally altering $\mathrm{W}$, large neurotoxic lesions of the LDT/PPT severely diminish PS with muscle atonia (Webster and Jones, 1988). Moreover, injections of the nonspecific cholinergic agonist, carbachol, into the pontomesencephalic RF elicit a state of PS with cortical activation and muscle atonia (Baghdoyan et al., 1987) (for review, see Jones, 1993; Brown et al., 2012), thus suggesting that the pontomesencephalic cholinergic neurons play a particularly important role in PS. To really understand their role, however, it is necessary to record from the cholinergic neurons. In attempts to do so, researchers found that neurons in the pontomesencephalic cholinergic cell area were heterogeneous, some discharging during $\mathrm{W}$ and PS, some during PS, and others during W (el Mansari et al., 1989; Steriade et al., 1990a; Kayama et al., 1992; Sakai, 2012). It was posited that the cholinergic neurons comprise both W/PS active and PS active neurons, whereas neighboring noradrenergic or serotoninergic neurons comprise $\mathrm{W}$ active neurons. Yet in neither the recording studies nor lesion studies could the activity or role of the neurons involved be attributed to the cholinergic neurons because they lie intermingled with equally numerous GABAergic and glutamatergic neurons in the LDT and PPT (Ford et al., 1995; Wang and Morales, 2009).

The aim of the present study was to record, label, and characterize the discharge of neurons in the pontomesencephalic cholinergic cell area in naturally waking/sleeping, head-fixed rats and 
subsequently identify them histochemically as cholinergic, GABAergic, or glutamatergic, as previously done in anesthetized rats (Boucetta and Jones, 2009). In this manner, the potential role of these distinct cell types can be determined in relation to EEG activity, EMG activity, and sleep-wake state. We thus used juxtacellular recording and labeling with Neurobiotin $(\mathrm{Nb})$ followed by histochemical staining using immunofluorescence (IF) for identifying cholinergic neurons with the vesicular ACh transporter (VAChT) and GABAergic neurons with glutamic acid decarboxylase (GAD), while assuming glutamatergic neurons comprised VAChT ${ }^{-} / \mathrm{GAD}^{-}$neurons (Boucetta and Jones, 2009; Hassani et al., 2009). In a subset of the latter, we moreover used a newly developed quadruple staining procedure using in situ hybridization (ISH) for identifying $\mathrm{Nb}^{+} / \mathrm{VAChT}^{-} / \mathrm{GAD}^{-}$neurons as glutamatergic with the vesicular glutamate transporter (VGluT2) (Wang and Morales, 2009). Focusing upon the LDT and SubLDT, we were able to determine the specific discharge profiles of cholinergic, GABAergic and "possibly" or "identified," glutamatergic neurons within the LDT, SubLDT, and adjoining medial part of the PPT (MPPT).

\section{Materials and Methods}

Animals and surgery. Experiments were performed on 40 adult male Long-Evans rats (200-250 g, Charles River). All procedures were approved by the McGill University Animal Care Committee and the Canadian Council on Animal Care. The animals were housed under a 12:12 h light-dark schedule with lights on from 7:00 A.M. to 7:00 P.M. and had free access to food and water. Surgery was performed under deep anesthesia (ketamine, xylazine, and acepromazine: $65 / 5 / 1 \mathrm{mg} / \mathrm{kg}$ in a mixture of $2 \mathrm{ml} / \mathrm{kg}$ initial dose and $1 \mathrm{ml} / \mathrm{kg}$ booster if needed, i.p.). Held within a stereotaxic frame (David Kopf Instruments), the rats were first implanted with electrodes for EEG (epidural stainless steel screws over olfactory bulb, anterior medial prefrontal, and retrosplenial cortices) and EMG (silver wire loops in neck muscles). Then, they were fitted with a metal U-shaped frame, which was fixed to the skull with acrylic cement and subsequently attached to a carriage adapter within the stereotaxic frame, as described previously (Lee et al., 2004). After recovery from surgery $(\sim 2 \mathrm{~d})$, the rats were gradually introduced to the head fixation in the carriage adapter while lying within a small Plexiglas box, which prevented twisting but not moving of their bodies and limbs. Animals were habituated to head fixation by repetitive sessions of increasing time duration over 1-2 weeks, until they were able to sleep or be awake comfortably for up to $6 \mathrm{~h}$ in a quiet environment.

Unit recording and labeling. One day before the experiment, rats were once again anesthetized (as described above) and operated for opening a hole over the posterior retrosplenial area on each side to allow passage of the recording pipettes at a $30^{\circ}$ angle to reach the pontomesencephalic tegmentum under the tentorium.

The day of the experiment, the dura mater was cut after local application of lidocaine. For recording, a glass micropipette $(\sim 1 \mu \mathrm{m}$ tip and $\sim 40 \mathrm{M} \Omega$ ) filled with $\sim 5 \% \mathrm{Nb}$ (Vector Laboratories) in $0.5 \mathrm{M} \mathrm{NaCl}$ solution was lowered into the pontomesencephalic tegmentum using a Kopf micropositioner (model 660, David Kopf Instruments). Single units were recorded and labeled using an intracellular amplifier (Neurodata IR283A, Cygnus Technology). The unit signal was amplified (2000×), digitized at a sampling rate of $8 \mathrm{kHz}$, and filtered (bandpass filter: $0.3-3 \mathrm{kHz}$ ) using a CyberAmp 380 (Molecular Devices) and acquired for online viewing with the Axoscope software (version 10.1, Molecular Devices). The unit was simultaneously recorded with EEG (digitized at a sampling rate of $250 \mathrm{~Hz}$ and filtered $0.5-60 \mathrm{~Hz}$ ), EMG (digitized at sampling rate of $250 \mathrm{~Hz}$ and filtered $10-100 \mathrm{~Hz}$ ), and video recordings of the animal behavior using Harmonie software (version 5.2, Stellate). A single unit was isolated and recorded for a minimum of 5 min and during at least one full sleep-wake cycle, including at least one $10 \mathrm{~s}$ epoch each of the three major states, active wake (aW), slow-wave sleep (SWS), and PS. Recording was performed in a quiet environment without any stimulation. After the recording of the unit, juxtacellular labeling was applied using depolarizing current pulses for modulation of the cell over a period of $\sim 2-5 \mathrm{~min}$.

Histochemistry. After full recording and labeling of only one unit on each side of the brain, the animals were perfused under anesthesia (Euthanyl, $\sim 100 \mathrm{ml} / \mathrm{kg}$, i.p.) with $\sim 400 \mathrm{ml}$ of $3 \%$ PFA fixative solution. The brains were removed, postfixed overnight in the fixative solution, immersed in a $30 \%$ sucrose solution for $2-3 \mathrm{~d}$, and then frozen at $-50^{\circ} \mathrm{C}$ and stored at $-80^{\circ} \mathrm{C}$. The brains were cut at $25 \mu \mathrm{m}$ on a freezing microtome.

For identification of Nb-labeled cells as cholinergic or GABAergic by IF, serial sections through the pontomesencephalic tegmentum were stained for Nb using Cy2-conjugated streptavidin (SA-Cy2, 1:2000, Jackson ImmunoResearch Laboratories) and mounted on slides for examination (using 70\% glycerol for coverslipping) by fluorescence microscopy. Sections containing the Nb-labeled neuron(s) were then floated off the slides and processed for IF (in Montreal, as previously applied) (Boucetta and Jones, 2009; Hassani et al., 2009), using primary antibodies for VAChT in goat (Millipore Bioscience Research Reagents) and GAD in mouse, anti-GAD67 (Millipore Bioscience Research Reagents) and secondary antibodies in donkey against goat (Cy5conjugated) or mouse (Cy3-conjugated) (Jackson ImmunoResearch Laboratories).

For identification of Nb-labeled noncholinergic/non-GABAergic cells as glutamatergic by ISH in a second part of the study, sections containing $\mathrm{Nb}^{+}$cells were processed for vesicular glutamate transporter (VGluT2) along with GAD (in Baltimore), by application and extension of a previously established technique combining IF and ISH (Wang and Morales, 2009). Sections with $\mathrm{Nb}^{+}$cells were first stained by IF for VAChT under RNase-free conditions, then viewed and photographed by fluorescence microscopy (above, in Montreal). After storage (and shipment) in 1\% PFA, they were processed (in Baltimore) for double ISH and detection of $\mathrm{Nb}$ by bright-field microscopy. They were incubated for $10 \mathrm{~min}$ in diethyl pyrocarbonate (DEPC)-treated phosphate buffer $(\mathrm{PB})$ with $0.5 \%$ Triton $\mathrm{X}-100$, rinsed with DEPC-treated PB, incubated in $0.2 \mathrm{~N} \mathrm{HCl}$, rinsed with DEPC-treated PB, and then acetylated in $0.25 \%$ acetic anhydride in $0.1 \mathrm{M}$ triethanolamine, $\mathrm{pH}$ 8.0. Sections were again rinsed with DEPC-treated $\mathrm{PB}$, postfixed with $4 \% \mathrm{PFA}$, and after a final rinse with DEPC-treated $\mathrm{PB}$, were hybridized for $16 \mathrm{~h}$ at $55^{\circ} \mathrm{C}$ in hybridization buffer (50\% formamide, $10 \%$ dextran sulfate, $5 \times$ Denhardt's solution, $0.62 \mathrm{M} \mathrm{NaCl}, 50 \mathrm{~mm}$ DTT, 10 mm EDTA, 20 mм PIPES, pH 6.8, 0.2\% SDS, $250 \mu \mathrm{g} / \mathrm{ml}$ salmon sperm DNA, $250 \mu \mathrm{g} / \mathrm{ml}$ tRNA) containing $\left[{ }^{35} \mathrm{~S}\right]$ - and $\left[{ }^{33} \mathrm{P}\right]$-labeled single-stranded antisense VGluT2 riboprobe at $10^{7} \mathrm{cpm} / \mathrm{ml}$, together with $600 \mathrm{ng}$ of a mix of $\mathrm{GAD}_{65}$ and $\mathrm{GAD}_{67}$ digoxigenin-labeled antisense riboprobes. The plasmid for VGluT2 (nucleotides 1704-2437, accession no. NM-053427) was generously provided by Dr. Robert H. Edwards (University of California). Plasmids that contained $\mathrm{GAD}_{65}$ (nucleotides 1-1758, accession no. NM012563) and $\mathrm{GAD}_{67}$ (nucleotides 1-1782, accession no. NM017007) were generously provided by Dr. Allan Tobin (University of California Los Angeles). The antisense digoxigenin riboprobes for $\mathrm{GAD}_{65}$ and $\mathrm{GAD}_{67}$ were produced by in vitro transcription using digoxigenin-11-UTP labeling mix (Roche Applied Science) and T3 RNA polymerase. Sections were treated with $4 \mu \mathrm{g} / \mathrm{ml}$ RNase A at $37^{\circ} \mathrm{C}$ for $1 \mathrm{~h}$, washed with SSC, $50 \%$ formamide at $55^{\circ} \mathrm{C}$ for $1 \mathrm{~h}$, and with SSC at $68^{\circ} \mathrm{C}$ for $1 \mathrm{~h}$. After the last SSC wash, sections were rinsed with Trisbuffered saline (20 mu Tris $\mathrm{HCl}, 0.5 \mathrm{M} \mathrm{NaCl}, \mathrm{pH}$ 8.2). Afterward, sections were incubated with an alkaline phosphatase-conjugated antibody against digoxigenin (Roche Applied Science) overnight at $4^{\circ} \mathrm{C}$ and the alkaline phosphatase reaction developed with nitroblue tetrazolium and 5-bromo-4-chloro-3-indolyl phosphate (Roche Applied Science), yielding a purple reaction product. After rinsing in $\mathrm{PB}$, positive $\mathrm{Nb}$ cells expressing GAD mRNA were photographed. For detection of the Nblabeled cells in bright-field microscopy, sections were rinsed in PBS and incubated with avidin-biotinylated HRP (Elite AB; Vector Laboratories) overnight at $4^{\circ} \mathrm{C}$. After rinsing, the peroxidase reaction was developed with $0.05 \% 3$, 3-diaminobenzidine- $4 \mathrm{HCl}(\mathrm{DAB})$ and $0.003 \%$ hydrogen peroxide $\left(\mathrm{H}_{2} \mathrm{O}_{2}\right)$. After further rinsing, sections were mounted on slides, air dried, dipped in Ilford K.5 nuclear tract emulsion (Polysciences; 1:1 dilution in double distilled water), and exposed in the dark at $4^{\circ} \mathrm{C}$ for 4 
Table 1. Frequency of anatomical and physiological characteristics among groups of cholinergic, GABAergic, and noncholinergic/non-GABAergic, including identified glutamatergic cells ${ }^{a}$

\begin{tabular}{|c|c|c|c|c|c|}
\hline & All cells & $\mathrm{Nb}^{+} / \mathrm{NAChT}^{+}$ & $\mathrm{Nb}^{+} / \mathrm{GAD}^{+}$ & $\mathrm{Nb}^{+} / \mathrm{NAChT}^{-} / \mathrm{GAD}^{-}$ & $\mathrm{Nb}^{+} / \mathrm{VAChT}^{-} / \mathrm{GAD}^{-}\left(\mathrm{VGluT2}^{+}\right)$ \\
\hline$N$ & 52 & 6 & 9 & 37 & (6) \\
\hline \multicolumn{6}{|l|}{ Anatomy } \\
\hline \multicolumn{6}{|l|}{ Area } \\
\hline LDT & 30 & 5 & 5 & 20 & (4) \\
\hline SubLDT & 14 & 0 & 3 & 11 & (2) \\
\hline MPPT & 8 & 1 & 1 & 6 & (0) \\
\hline \multicolumn{6}{|l|}{$\operatorname{Size}^{b}$} \\
\hline Small $(\leq 15 \mu \mathrm{m})$ & 12 & 0 & 4 & 8 & (2) \\
\hline Medium-large $(>15 \mu \mathrm{m})$ & 34 & 6 & 4 & 24 & (4) \\
\hline \multicolumn{6}{|l|}{ Physiology } \\
\hline \multicolumn{6}{|l|}{ Discharge profile ${ }^{c}$} \\
\hline W/PS-max & 29 & 6 & 5 & 18 & (3) \\
\hline PS-max & 16 & 0 & 4 & 12 & (1) \\
\hline W-max & 7 & 0 & 0 & 7 & (2) \\
\hline \multicolumn{6}{|l|}{ Firing frequency ${ }^{d}$} \\
\hline Slow $(<14.5 \mathrm{~Hz})$ & 22 & 6 & 2 & 14 & (1) \\
\hline Fast $(\geq 14.5 \mathrm{~Hz})$ & 30 & 0 & 7 & 23 & (5) \\
\hline \multicolumn{6}{|l|}{ Firing pattern ${ }^{e}$} \\
\hline Tonic regular & 12 & 2 & 1 & 9 & (2) \\
\hline Tonic irregular & 20 & 4 & 3 & 13 & (1) \\
\hline Phasic cluster & 14 & 0 & 3 & 11 & (2) \\
\hline Phasic burst & 6 & 0 & 2 & 4 & (1) \\
\hline
\end{tabular}

${ }^{a}$ Numbers $(n)$ of Nb-labeled cells identified as $\mathrm{VAChT}^{+}, \mathrm{GAD}^{+}$, or $\mathrm{VAChT}{ }^{-} / \mathrm{GAD}^{-}$. According to $\chi^{2}$ tests of association, significant differences in frequencies were found only on "Firing frequency" parameter $\left(\chi^{2}=9.97\right.$, df $=2, p=$ 0.007). Numbers of VGluT2 ${ }^{+}$cells, which represent a subset of the $\mathrm{VAChT}^{-} / \mathrm{GAD}^{-}$cells, are also presented in parentheses.

${ }^{b}$ According to long axis of whole cell bodies $(n=46)$.

'According to classification of units based on statistical analysis (by ANOVA) of significant differences in discharge rate across and between the three principle states: aW (W), SWS (S), and PS (PS), indicating the state(s) during which the highest rate occurred (-max).

${ }^{d}$ According to instantaneous firing frequency calculated from the peak of the primary mode of the interspike interval histogram during the state of maximal discharge.

${ }^{e}$ Firing pattern determined by comparison of the instantaneous firing frequency and average discharge rate during the state of maximal discharge.

weeks before development for the visualization of neurons expressing VGluT2 mRNA.

Data analysis. Electrophysiological records of EEG and EMG were scored for analysis with unit activity in $10 \mathrm{~s}$ epochs using MATLAB (version 5.3, MathWorks). As described previously (Maloney et al., 1997; Lee et al., 2004), six sleep-wake stages were scored as follows: aW, quiet wake ( $\mathrm{qW}$ ), transition to slow-wave sleep (tSWS), SWS, transition to paradoxical sleep (tPS), and PS. Briefly, aW was scored when rhythmic $\theta$ activity $(\sim 6-8 \mathrm{~Hz})$ occurred along with high-frequency EEG and increased muscle tone during the $10 \mathrm{~s}$ epoch; $\mathrm{qW}$ when irregular slower activity $(\sim 4.5-6 \mathrm{~Hz})$ was present along with high-frequency EEG and moderate muscle tone; tSWS when slower irregular activity $(<4.5 \mathrm{~Hz})$ was present along with spindles $(\sim 10-14 \mathrm{~Hz})$; SWS when irregular, high amplitude slow-wave $\delta$ activity $(\sim 1-4 \mathrm{~Hz})$ was present for $>75 \%$ of the epoch; tPS when relatively continuous spindle activity $(\sim 9-14 \mathrm{~Hz})$ was present and progressed toward rhythmic $\theta$ activity $(\sim 6-8 \mathrm{~Hz})$; and PS when rhythmic $\theta$ activity $(\sim 6-8 \mathrm{~Hz})$ was relatively continuous and accompanied by high-frequency EEG (riding on $\theta$ waves) and low muscle tone for $>75 \%$ of the epoch. Transitional epochs between stages, where neither stage represented $>75 \%$ of the epoch, were not scored or included in the analysis. The average number of bouts and average duration in seconds per bout of each stage during recording of units $(n=52)$ were as follows: aW, $2.52 \pm 0.33$ bouts and $13.53 \pm 0.71 \mathrm{~s} ; \mathrm{qW}, 3.14 \pm 0.44$ bouts and $13.76 \pm 0.72 \mathrm{~s}$; tSWS, $3.94 \pm 0.51$ bouts and $19.11 \pm 1.15 \mathrm{~s}$; SWS, $3.44 \pm 0.38$ bouts and $38.80 \pm 2.58 \mathrm{~s}$; tPS, $1.52 \pm 0.09$ bouts and $23.21 \pm 1.53 \mathrm{~s}$; and PS, $1.02 \pm 0.02$ bouts and $43.08 \pm 3.79 \mathrm{~s}$. For the unit activity, the average discharge rate was calculated as spikes/s per stage. Units were classified into sleep-wake subgroups according to whether their discharge rate varied significantly across the three major states of aW, SWS, and PS (by ANOVA, $p<0.05$ ) and, if so, according to the state(s) in which their maximal (along with their minimal) discharge rate occurred ( $p<0.01$ according to Bonferroni corrected post hoc paired comparisons) (Lee et al., 2004).

For analysis of simple correlations between unit spike rate with EEG or EMG activity across sleep-wake stages, amplitudes of EEG frequency bands or EMG were obtained by spectral analysis: $\delta(1.0-4.5 \mathrm{~Hz}), \theta$ $(4.5-8.5 \mathrm{~Hz}$, also used in a ratio of $\theta / \delta), \sigma(9.0-14.0 \mathrm{~Hz}), \beta 1(14.5-18.5$ $\mathrm{Hz}), \beta 2(19.0-30.0 \mathrm{~Hz})$, and $\gamma(30.5-58.0 \mathrm{~Hz})$ and EMG $(30-100 \mathrm{~Hz})$ (Maloney et al., 1997). For statistical analysis, EEG and EMG values were taken only from recordings without artifact. Simple Pearson correlations were performed between average discharge rate and EEG frequency band or EMG amplitudes per unit, and correlation coefficients expressed as mean \pm SEM of the $r$ values.

Based upon the proportions of sleep-wake stages and accompanying variations in EEG activity, the sleep-wake cycle recorded in the headfixed preparation is similar to that of the freely moving rat in our laboratory recorded during the day, when the rat sleeps the majority of the time (Maloney et al., 1997, 1999). On the other hand, the amount of aW is less for our recorded units because units are often difficult to hold during brisk movements of the body, which the rat can and does perform occasionally in the head-fixed set-up. The epochs of aW in the head-fixed commonly show brief periods of small movements with increased EMG and accompanying $\theta$ EEG activity. The level of $\gamma$ activity also does not often reach its maximal level during aW in the head-fixed rat, which it reaches during periods of continuous movement during aW in the freely moving rat and which can be equal in amplitude to the $\gamma$ during PS (Maloney et al., 1997). Here in the head-fixed rat, $\gamma$ is generally somewhat lower during aW than during PS. For this reason, we classify units as W/PS when their rate is significantly higher in aW and PS than in SWS, but we do not highlight or interpret cases in which the rate is lower in W than in PS, as is true for most of the W/PS-max active units. We think that the aW rates could be higher during maximal activity in freely moving animals, particularly during the night. However, we consider that the rates that occur during PS when $\gamma$ is maximal and thus, the correlation between the rates with $\gamma$ across the sleep-wake cycle reflects the relationship of the unit discharge to cortical activation in our head-fixed preparation. Those units which discharge maximally during aW and minimally during PS could also likely discharge at higher rates during continual movement but here nonetheless show a positive correlation with EMG amplitude across the sleep-wake cycle. 
A
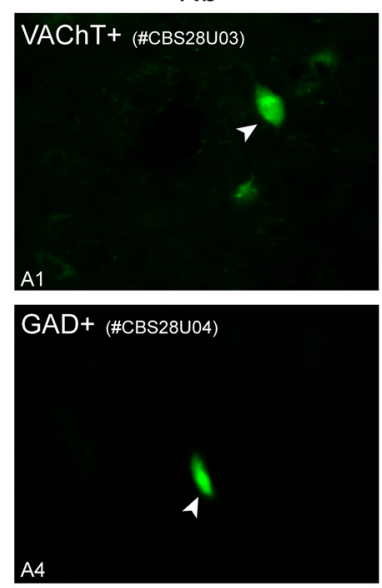

$\mathrm{B}$
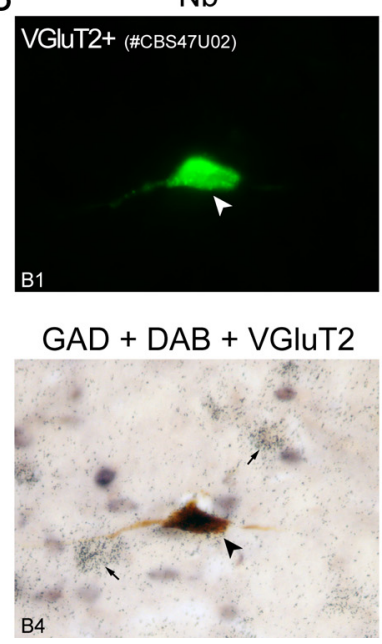
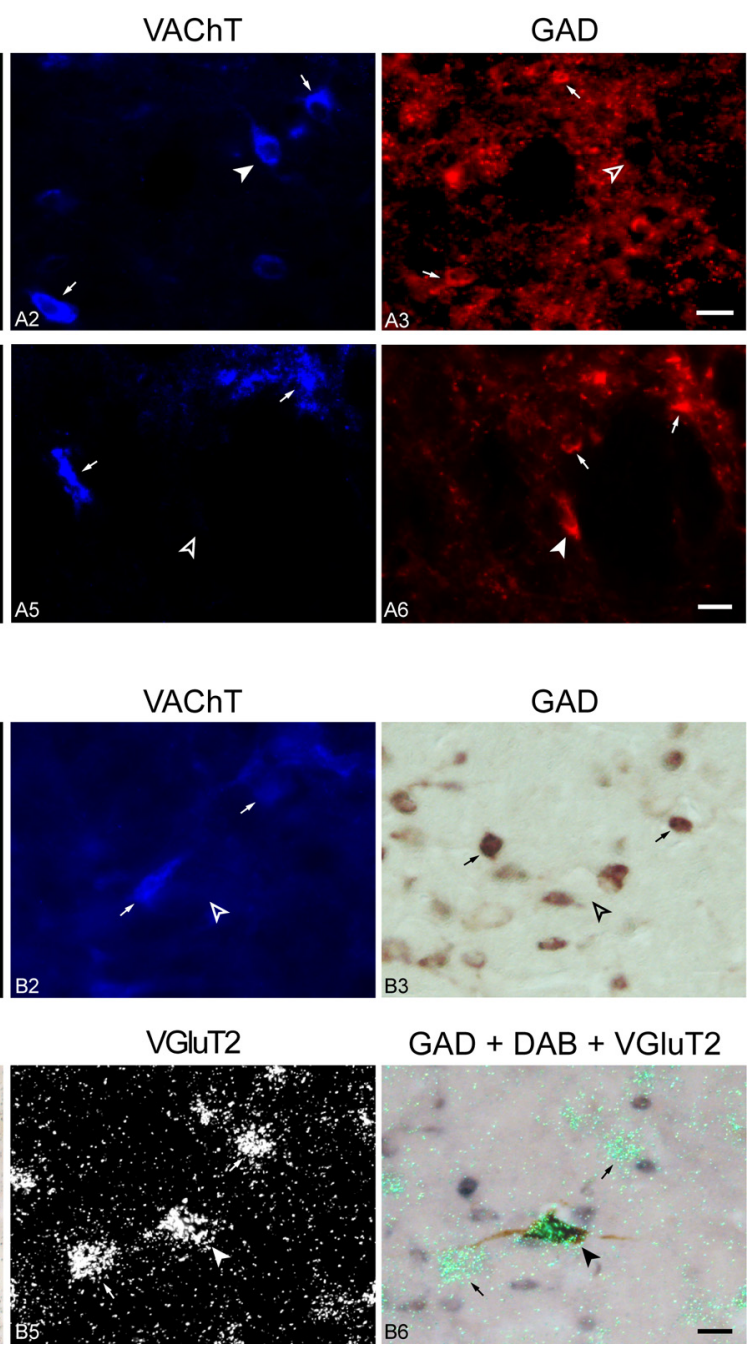

$\mathrm{GAD}+\mathrm{DAB}+$ VGluT2

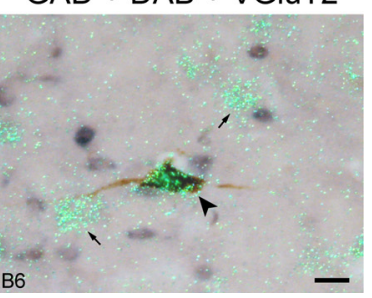

Figure 1. Staining of Nb-labeled cholinergic, GABAergic, and glutamatergic neurons. $A$, IF staining of recorded and $\mathrm{Nb}$-labeled neurons (green, filled arrowheads), which were stained for VAChT (blue) or GAD (red). $A 1-A 3, \mathrm{Nb}^{+}$cell shown to be cholinergic (CBS28U03) was immunopositive for VAChT (filled arrowhead), immunonegative for GAD (open arrowhead), and located among other VAChT ${ }^{+}$and GAD ${ }^{+}$cells (small arrows) in the LDT (Fig. 2, mapped as largest red circle). This cell was classified as "W/PS-

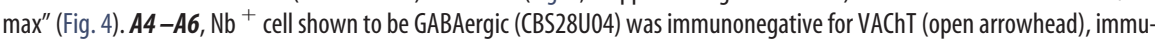
nopositive for GAD (filled arrowhead), and located among other VAChT ${ }^{+}$and $\mathrm{GAD}^{+}$cells (small arrows) in the SubLDT (Fig. 2, mapped as largest filled green triangle). This cell was classified as a PS-max cell (Fig. 7). B, Staining by IF (B1, B2) and ISH (B3-B6) of an $\mathrm{Nb}^{+}$cell shown to be glutamatergic (CBS47U02). The $\mathrm{Nb}^{+}$cell (B1, green Cy2 staining; $\boldsymbol{B} 4$, brown DAB staining, filled arrowheads) was established as VAChT-negative by IF ( $\boldsymbol{B} 2$, blue, open arrowhead), then established as $G A D^{-}$by ISH ( $\boldsymbol{B} 3$, purplegray, open arrowhead) and VGluT2 ${ }^{+}$by ISH ( $B 5, B 6$, silver grains, filled arrowhead). The silver grains from the autoradiography appear white in dark-field illumination (B5) and greenish in bright-field epi-illumination (B6). The $\mathrm{Nb}^{+} / \mathrm{VGluT2}^{+}$cell was located among other $\mathrm{VAChT}^{+}, \mathrm{GAD}^{+}$, and VGluT2 ${ }^{+}$cells (small arrows) in the SubLDT (Fig. 2, largest open red diamond). The cell was classified as a W-max active cell (Fig. 9). Scale bars, $20 \mu \mathrm{m}$.

Each unit was further analyzed and distinguished according to its firing properties during the maximally active state. The instantaneous firing frequency was calculated from the interspike interval histogram (ISIH), as the reciprocal of the peak interspike interval. From this firing frequency, the unit was classified as "fast" ( $\geq 14.5 \mathrm{~Hz}$ ) or slow firing $(<14.5 \mathrm{~Hz})$, as according to firing rates above or below $\beta$ EEG frequencies (Maloney et al., 1997; Lee et al., 2004). Then, each unit was classified as "tonic" or "phasic" by comparing the instantaneous firing frequency with the average discharge rate, or specifically the corresponding interspike interval of the average discharge rate to the interspike interval mode and distribution. If the average discharge rate interval fell within 95\% (2 $\mathrm{SDs}$ ) of the interspike interval mode, the unit was classified as "tonic," if outside 95\%, as "phasic." Among the tonically firing units, their discharge was further distinguished as "tonic regular" if their average discharge rate interval fell within $86.6 \%$ (1.5 SDs) of the interspike interval distribution or as "tonic irregular" if outside. Among phasically firing units, their firing was further distinguished according to the instantaneous firing frequency as comprised by highfrequency spike bursts, as $>80 \mathrm{~Hz}$, or lower frequency spike clusters, as $<80 \mathrm{~Hz}$ (Alonso et al., 1996; Manns et al., 2000). Also from the state of maximal discharge, rhythmicity of firing and its frequency was assessed by using autocorrelation histograms and the potential relationship of the firing to the EEG by using spike-triggered averages. For assessing wave form and duration of spikes, all spikes (10120) were averaged across stages for each cell. To avoid variations in zero on the return to baseline after the negative deflection, the measurement was based upon second zero crossing but calculated with an offset from zero corresponding to $10 \%$ of the positive peak amplitude.

All analyses of raw data were done using MATLAB (version 5.3, MathWorks) and statistical analysis using Systat 13.0 (SPSS). Figures were made using Adobe Photoshop CS (Adobe Systems) for photomicrographs and Adobe Illustrator CS (Adobe Systems) for plotting electrophysiological data.

A total of 111 units were recorded in the pontomesencephalic tegmentum across a full sleep-waking cycle. According to their average discharge rate across sleep-wake states, the neurons could be classified into five different functional subgroups: (1) those that discharged maximally during both aW and PS and minimally during SWS, as W/PS-max active cells $(n=55)$; (2) those that discharged minimally during aW and maximally during PS, as PS-max active cells $(n=31)$; (3) those that discharged maximally during aW and minimally during PS, as W-max active cells ( $n=$ $21)$; (4) those that did not show significant variation in their discharge rate across sleepwake states, as wsp-equivalent (wsp-eq) cells ( $n$ $=3$ ); and (5) one that discharged maximally during SWS as a SWS-max active cell $(n=1)$.

Of 111 recorded units, 101 were maintained long enough to be submitted to juxtacellular labeling; and of these, 75 (74\%) were successfully labeled with $\mathrm{Nb}\left(\mathrm{Nb}^{+}\right)$. Using Neurolucida (version 9, MicroBrightField), the $\mathrm{Nb}$ labeled cells were mapped onto a computer resident atlas. Constructed according to cytoarchitectonic features and immunohistochemical staining of neurons (Jones and Cuello, 1989; Jones, 1990, 1995), this atlas shows the cholinergic neurons as distributed in a relatively continuous manner through the dorsolateral pontomesencephalic tegmentum and located within the LDT, SubLDT, MPPT, and LPPT, through which they are intermingled with GABAergic and glutamatergic neurons (Ford et al., 1995; Wang and Morales, 2009). The cholinergic neurons situated in the periventricular and periaqueductal gray are situated in the commonly called LDT, as here. Those extending beneath the gray were originally included in the PPT by Armstrong et al. (1983) but are situated by us in the SubLDT, as similarly called the sublateral dorsal nucleus (SLD) in the atlas of Swanson (1992) and the ventral LDT (LDTgV) in the atlas of Paxinos and Watson (1986). Those cholinergic neurons surrounding the superior cerebellar peduncle, which were originally localized collectively to the PPT by Armstrong et al. (1983), were divided by us into medial (MPPT, medial and ventral to the peduncle) and lateral (LPPT, lateral 
and dorsal to the peduncle and its decussation) divisions (Jones, 1990; Ford et al., 1995), which respectively correspond approximately to the pars dissipata and compacta of the PPT (Armstrong et al., 1983; Rye et al., 1987; Wang and Morales, 2009). The MPPT and LPPT are shown as one pedunculopontine nucleus (PPN) in the atlas of Swanson (1992) and respectively correspond approximately to the subpeduncular tegmental nucleus ( $\mathrm{SPTg}$ ) and the pedunculopontine tegmental nucleus (PPTg) in the atlas of Paxinos and Watson (1986).

Of the $\mathrm{Nb}^{+}$cells in this study, 52 were located within the pontomesencephalic cholinergic cell area, including the LDT, SubLDT, MPPT nuclei, or the zones immediately surrounding each nucleus (and thus included in the adjacent nucleus), where the cholinergic cells were previously mapped by us (Jones, 1990; Ford et al., 1995). The remaining 23 were located in the adjacent central gray (CG, $n=$ $8)$, oral pontine reticular formation $(\mathrm{PnO}$, $n=6$ ), dorsomedial tegmental nucleus (DMT, $n=4)$, deep mesencephalic reticular nucleus (DpMe, $n=3)$, subcoeruleus $\alpha$ (SubC $\alpha, n=1)$ or dorsal raphe (DR, $n=1)$ outside the zone of the pontomesencephalic cholinergic neurons.

As done previously (Boucetta and Jones, 2009), Nb-labeled cells were judged as positive $(+)$ or negative $(-)$ for VAChT or GAD in the immunohistochemical material only when immunostaining was clearly evident within cells in the immediate surround of the LDT/SubLDT or MPPT. Those cells that were judged to be $\mathrm{VAChT}^{-} / \mathrm{GAD}^{-}$were considered as "possibly" glutamatergic because LDT/PPT neurons were previously shown to comprise three distinct subpopulations of choline-acetyl transferase ${ }^{+}, \mathrm{GAD}^{+}$, or VGluT2 ${ }^{+}$cells (Wang and Morales, 2009). However, it is recognized that negative staining in histochemistry cannot be considered as unequivocal proof of absence of one protein or presence of another protein and thus of the chemical identity of a neuron. In the second part of the present study, therefore, quadruple histochemical staining (above) was applied in a small subset of the Nb-labeled cells to reveal VGluT2 together with GAD using ISH and VAChT using IF. Among these cells, $\mathrm{VAChT}^{-} / \mathrm{GAD}^{-}$neurons that were VGluT2 ${ }^{+}$were distinguished as "identified" glutamatergic cells.

\section{Results}

\section{Identification, localization, and classification of cell groups}

Of 75 cells successfully recorded across a full sleep-waking cycle and labeled with $\mathrm{Nb}\left(\mathrm{Nb}^{+}\right), 52$ cells were located in the region of the pontomesencephalic cholinergic cell area within or immediately surrounding the LDT, SubLDT, or MPPT (Table 1). Of these, $6 \mathrm{Nb}^{+}$cells were positively stained by IF for VAChT $\left(\mathrm{Nb}^{+} / \mathrm{VAChT}^{+}\right.$; Fig. 1A1-A3; Table 1) and thus cholinergic. Nine were positive for GAD $\left(\mathrm{Nb}^{+} / \mathrm{GAD}^{+}\right.$; Table 1$)$, of which 7 were stained by IF (Fig. $1 A 4-A 6)$ and 2 by ISH, and thus GABAergic. The remaining 37 were negative for both VAChT and GAD $\left(\mathrm{Nb}^{+} / \mathrm{VAChT}^{-}\right.$/ $\mathrm{GAD}^{-}$; Table 1) and thus considered as possibly glutamatergic. tegmental nucleus.
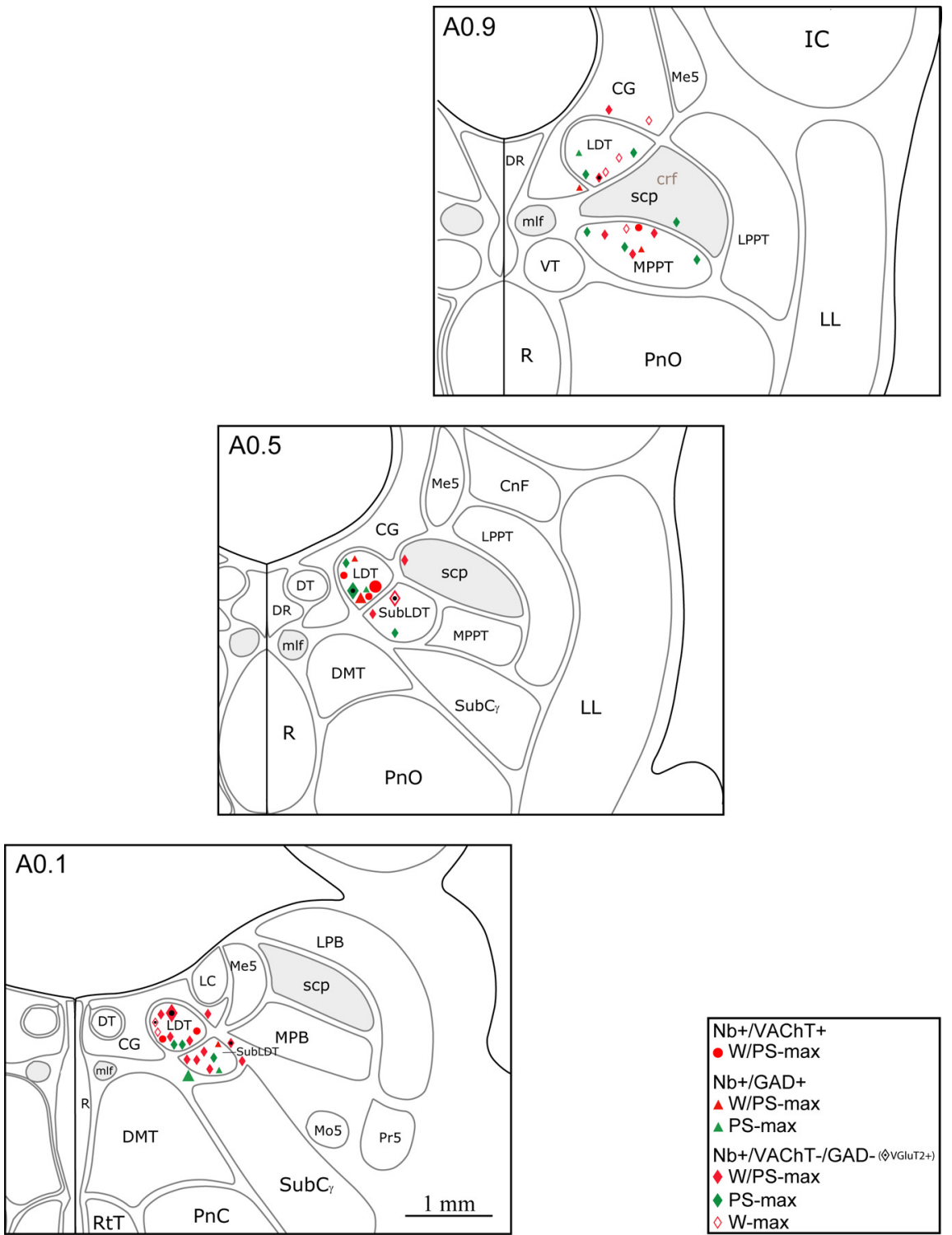

Figure 2. Distribution of $\mathrm{Nb}$-labeled cells in the pontomesencephalic cholinergic cell area. The recorded, Nb-labeled cells ( $n=$ 52) were histochemically identified as cholinergic $\left(\mathrm{Nb}^{+} / \mathrm{NAChT}^{+}\right.$, circles), as $\mathrm{GABAergic}\left(\mathrm{Nb}^{+} / \mathrm{GAD}^{+}\right.$, triangles), or as possibly or identified glutamatergic ( $\mathrm{Nb}^{+} / \mathrm{NAChT}^{-} / \mathrm{GAD}^{-}$, diamonds; or VGluT2 ${ }^{+}$, diamonds with black dots). They were further distinguished according to their functional subgroup as "W/PS-max" (red filled symbols), "PS-max" (green filled symbols), or "W-max" (red open symbols). Through appropriate levels (anterior, A0.9, A0.5, or A0.1 mm to interaural zero) of the pontomesencephalic tegmentum, cells were included and mapped if present in the LDT, SubLDT, or MPPT nuclei or surrounding zones where cholinergic cells are located. The largest symbols correspond to representative cells of each subgroup, for which the histochemical staining and/or physiology is illustrated (Figs. 1,4,5, 6,7,8,9). CnF, Cuneiform nucleus; crf, central reticular fasciculus; DT, dorsal tegmental nucleus; IC, inferior colliculus; LC, locus coeruleus; LL, lateral lemniscus; LPB, lateral parabrachial nucleus; Me5, mesencephalic trigeminal nucleus; mlf, medial longitudinal fasciculus; Mo5, motor trigeminal nucleus; MPB, medial parabrachial nucleus; PnC, pontine reticular nucleus, caudal part; $\mathrm{Pr} 5$, principal sensory trigeminal nucleus; $\mathrm{R}$, raphe nuclei; $\mathrm{RtT}$, reticulotegmental nucleus of the thalamus; scp, superior cerebellar peduncle; SubC $\gamma$, subcoeruleus $\gamma$; SubLDT, sublaterodorsal tegmental nucleus; VT, ventral

For 6 of the latter cells, their identity as glutamatergic was confirmed by ISH for VGluT2 (Fig. 1B1-B6). Morphologically, $\mathrm{Nb}^{+} / \mathrm{VAChT}^{+}$cells were all medium to large in size $(>15 \mu \mathrm{m}$ in long axis), whereas a significant proportion of the $\mathrm{Nb}^{+} / \mathrm{GAD}^{+}$ and $\mathrm{Nb}^{+} / \mathrm{VAChT}^{-} / \mathrm{GAD}^{-}$cells, along with the $\mathrm{Nb}^{+} / \mathrm{VAChT}^{-}$/ $\mathrm{GAD}^{-} / \mathrm{VGluT}^{+}{ }^{+}$cells, were small in size $(\leq 15 \mu \mathrm{m}$; Table 1$)$. On average, however, the cell sizes (long axis) did not differ significantly among the $\mathrm{Nb}^{+} / \mathrm{VAChT}^{+}(22.65 \pm 1.04 \mu \mathrm{m}, n=6)$, $\mathrm{Nb}^{+} / \mathrm{GAD}^{+}(17.18 \pm 1.92, n=8)$, and $^{+} \mathrm{Nb}^{+} / \mathrm{VAChT}^{-} / \mathrm{GAD}^{-}$ 
Table 2. Electrophysiological properties of cholinergic, GABAergic, and noncholinergic/nonGABAergic, including identified glutamatergic, cell groups ${ }^{a}$

\begin{tabular}{|c|c|c|c|c|}
\hline Cell type and subgroup & $n$ & Spike duration (ms) & Instantaneous firing frequency $(\mathrm{Hz})$ & Average discharge rate $(\mathrm{Hz})$ \\
\hline \multicolumn{5}{|l|}{$\mathrm{VAChT}^{+b}$} \\
\hline \multicolumn{2}{|l|}{$\mathrm{GAD}^{+c}$} & $1.65 \pm 0.13^{c}$ & $7.73 \pm 1.23^{c}$ & $4.27 \pm 1.56$ \\
\hline PS-max & 4 & $0.96 \pm 0.09$ & $38.13 \pm 13.63$ & $16.85 \pm 2.27$ \\
\hline Average & 9 & $1.00 \pm 0.05^{b, d}$ & $47.88 \pm 10.84$ & $14.25 \pm 2.24$ \\
\hline \multicolumn{5}{|l|}{$\mathrm{VAChT}^{-} / \mathrm{GAD}^{-d}$} \\
\hline W-max & 7 & $1.81 \pm 0.20$ & $10.10 \pm 3.35$ & $4.23 \pm 2.36$ \\
\hline Average & 37 & $1.50 \pm 0.08^{c}$ & $39.82 \pm 8.19$ & $10.24 \pm 1.60$ \\
\hline \multicolumn{5}{|l|}{$\left(\right.$ VGluT2 $\left.^{+}\right)$} \\
\hline W/PS-max & (3) & $(1.33 \pm 0.17)$ & $(15.83 \pm 7.99)$ & $(5.32 \pm 2.39)$ \\
\hline PS-max & (1) & $(1.09)$ & $(200.00)$ & $(9.42)$ \\
\hline W-max & (2) & $(1.39 \pm 0.16)$ & $(20.40 \pm 2.90)$ & $(12.02 \pm 5.39)$ \\
\hline (Average) & 52 & $F=6.39 ; \mathrm{df}=2,49 ; p=0.003$ & $F=1.62 ; \mathrm{df}=2,49 ; p=0.21$ & $F=2.28 ; \mathrm{df}=2,49 ; p=0.11$ \\
\hline
\end{tabular}

cells $(19.07 \pm 1.11, n=32)(F=1.54 ; \mathrm{df}=2,43 ; p=0.23)$ or $\mathrm{Nb}^{+} / \mathrm{VAChT}^{-} / \mathrm{GAD}^{-} / \mathrm{VGluT}^{+}{ }^{+}$cells $(18.95 \pm 4.71, n=6)$ $(F=0.98 ; \mathrm{df}=2,17 ; p=0.40)$.

The $\mathrm{Nb}^{+} / \mathrm{VAChT}^{+}, \mathrm{Nb}^{+} / \mathrm{GAD}^{+}$, and $\mathrm{Nb}^{+} / \mathrm{VAChT}^{-} /$ $\mathrm{GAD}^{-}$cells along with the $\mathrm{Nb}^{+} / \mathrm{VAChT}^{-} / \mathrm{GAD}^{-} / \mathrm{VGluT}^{+}$ cells were distributed through the caudal-rostral extent of the LDT $(n=30)$, its ventral extension beneath the central gray in the SubLDT $(n=14)$, or more ventrally and rostrally beneath the superior cerebellar peduncle in the MPPT $(n=8)$ (Fig. 2; Table 1) (Ford et al., 1995). According to their sleep-wake discharge profile, the LDT, SubLDT, and MPPT neurons comprised three functional subgroups: (1) those that discharged maximally during W and PS, as W/PS-max active cells (56\%); (2) those that discharged maximally during PS, as PS-max active cells (31\%); and (3) those that discharged maximally during waking, as $\mathrm{W}$-max active cells (13\%; Table 1). Whereas all $\mathrm{Nb}^{+} / \mathrm{VAChT}^{+}$cells were W/PS-max active cells, $\mathrm{Nb}^{+} / \mathrm{GAD}^{+}$ and $\mathrm{Nb}^{+} / \mathrm{VAChT}^{-} / \mathrm{GAD}^{-}$cells along with $\mathrm{Nb}^{+} / \mathrm{VAChT}^{-} /$ $\mathrm{GAD}^{-} / \mathrm{VGluT}^{+}{ }^{+}$cells included W/PS-max and PS-max cells. $\mathrm{Nb}^{+} / \mathrm{VAChT}^{-} / \mathrm{GAD}^{-}$along with the $\mathrm{Nb}^{+} / \mathrm{VAChT}^{-} / \mathrm{GAD}^{-} /$ VGluT2 ${ }^{+}$cells included, additionally, $\mathrm{W}$-max active cells (Fig. 2; Table 1). In their distribution through the LDT, SubLDT, and MPPT, the different functional subgroups and transmitter phenotypes were intermingled with no evidence of selective clustering (Fig. 2).

The $\mathrm{Nb}^{+}$cells that were distributed outside the cholinergic cell area in the surrounding pontomesencephalic tegmentum (data not shown; see Materials and Methods) were comprised by two $\mathrm{Nb}^{+} / \mathrm{GAD}^{+}$cells, both W/PS-max, and $21 \mathrm{Nb}^{+} / \mathrm{VAChT}^{-} /$ $\mathrm{GAD}^{-}$cells, with 1 VGluT2 ${ }^{+}$cell, including $6 \mathrm{~W} / \mathrm{PS}-\mathrm{max}, 6$ PSmax, $5 \mathrm{~W}$-max, 3 wsp-eq, and 1 SWS-max.

Physiologically, the three cell types in the LDT, SubLDT, and MPPT had overlapping characteristics (Tables 1 and 2). The waveform of their spikes varied in duration but did not reveal any other distinctive features among the three (Fig. 3). Although the $\mathrm{Nb}^{+} / \mathrm{VAChT}^{+}$cells and the $\mathrm{Nb}^{+} / \mathrm{VAChT}^{-} / \mathrm{GAD}^{-}$cells differed significantly from the $\mathrm{GAD}^{+}$cells in the average duration of their spikes, the $\mathrm{Nb}^{+} / \mathrm{VAChT}^{+}$cells did not differ significantly from the $\mathrm{Nb}^{+} / \mathrm{VAChT}^{-} / \mathrm{GAD}^{-}$cells or $\mathrm{Nb}^{+} / \mathrm{VAChT}^{-} / \mathrm{GAD}^{-} /$ VGluT2 ${ }^{+}$cells in this regard (Table 2 ). Across the three types, the spike durations varied to the degree that individual cells could not be identified with certainty as cholinergic, GABAergic, or glutamatergic during recording (Fig. 3). Moreover, despite certain differences, the three cell types and functional subgroups could also not be clearly distinguished or unequivocally identified by their instantaneous firing frequencies or average discharge rates given overlapping variation in these parameters (Fig. 3; Tables 2 and 3), as presented in detail below (see Figs. $4,5,7,7,8-9)$.

\section{W/PS-max active neurons}

The W/PS-max active neurons represented the largest subgroup found in the LDT, SubLDT, and MPPT $(n=29)$ and included all three cell types, $\mathrm{Nb}^{+} / \mathrm{VAChT}^{+}, \mathrm{Nb}^{+} / \mathrm{GAD}^{+}$, and $\mathrm{Nb}^{+}$/ $\mathrm{VAChT}^{-} / \mathrm{GAD}^{-}$(with VGluT2 ${ }^{+}$). They discharged maximally during aW and PS and minimally during SWS.

$\mathrm{Nb}^{+} / \mathrm{VAChT}^{+}$, cholinergic neurons $(n=6)$ represented $21 \%$ of the W/PS-max active subgroup (Table 1). As characteristic of this subgroup, all $\mathrm{VAChT}^{+}$cells discharged at significantly higher rates during aW and PS than during SWS. Although some ( 2 of 6) discharged at higher rates during aW than PS, most (4 of 6) discharged at their highest rate during PS, as shown for the representative cell in Figure 4 (CBS28U03, also shown as $\mathrm{VAChT}^{+}$in Fig. 1A). On average, they discharged at slow rates during aW $(2.28 \pm 1.31 \mathrm{~Hz})$, progressively slower rates in $\mathrm{qW}$ and tSWS to be virtually silent during SWS $(0.04 \pm 0.01 \mathrm{~Hz})$, and then increased their rate during $\mathrm{tPS}$ to reach maximal rates during PS $(3.73 \pm 1.46 \mathrm{~Hz}$ ) (Table 3; Fig. $4 A-C)$. As evident by the change in rates, which occurred during the transitional $(t)$ stages leading to SWS and PS, the $\mathrm{VAChT}^{+}$cells anticipated changes in EEG activity by slowing in the progression from aW, through $\mathrm{qW}$ and tSWS before SWS and accelerating in the progression during tPS before PS. On average, for cells in which the EEG state changes 
A
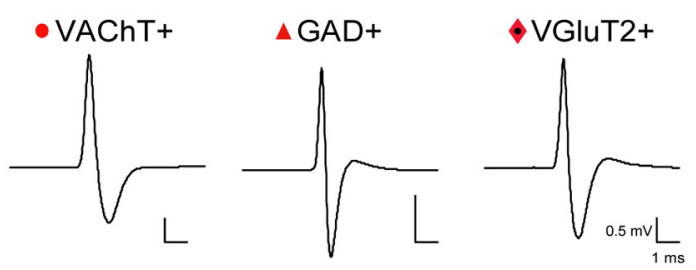

B

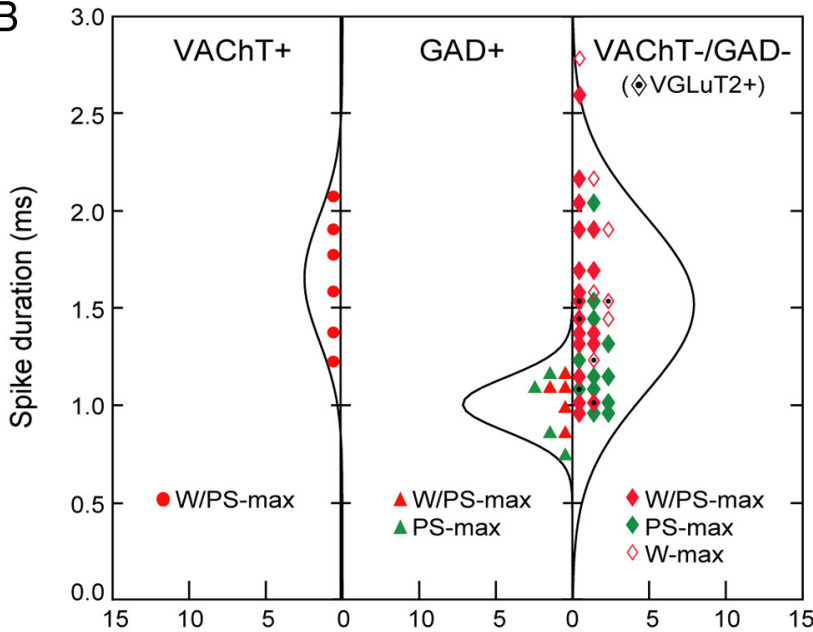

$\mathrm{C}$
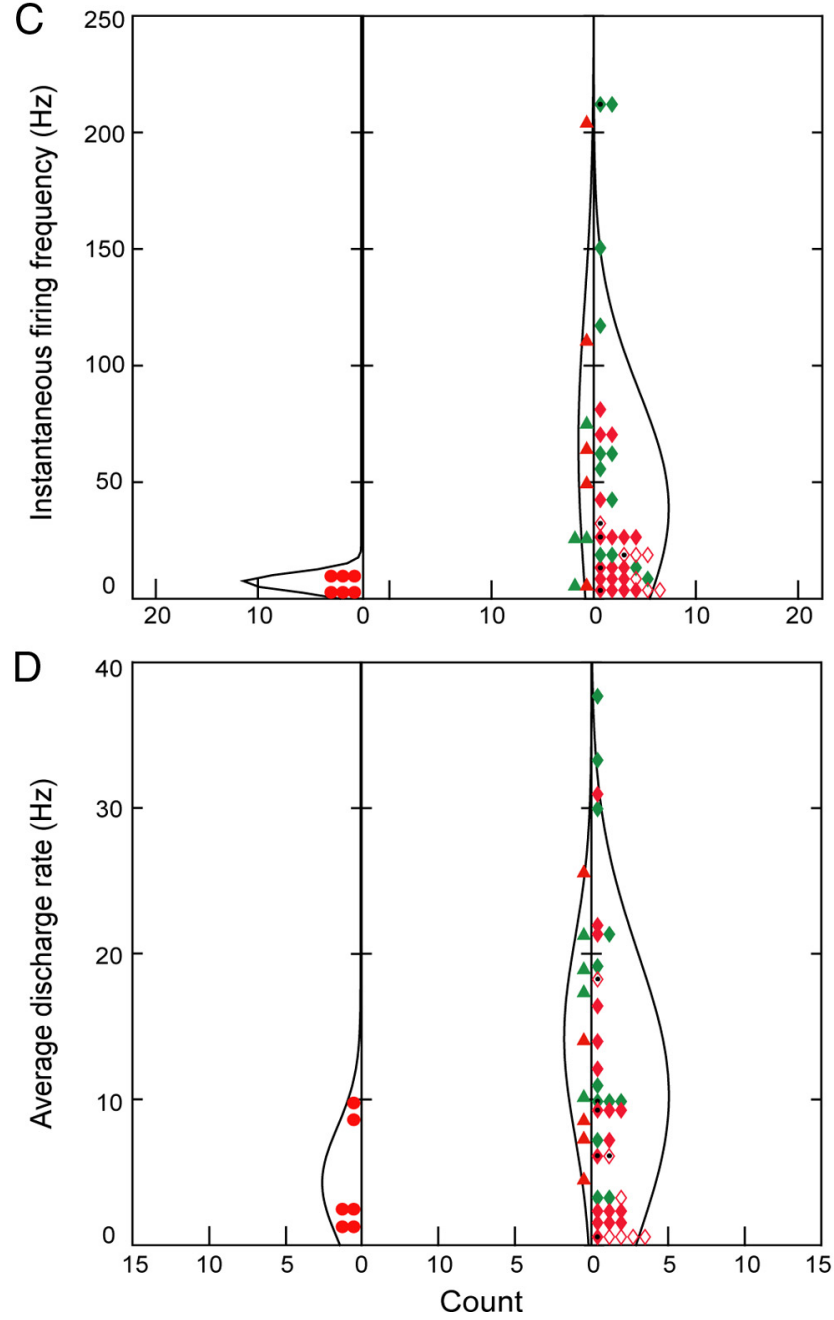

Figure 3. Comparison of spikes among cholinergic, GABAergic, and glutamatergic neurons. $A$, Spikes (average) from identified $\mathrm{Nb}^{+} / \mathrm{NAChT}^{+} \mathrm{W} / \mathrm{PS}$-max cell (left, shown in Fig. 4), $\mathrm{Nb}^{+} /$ $\mathrm{GAD}^{+}$W/PS-max cell (middle, shown in Fig. 5), and $\mathrm{Nb}^{+} / \mathrm{NAChT}^{-} / \mathrm{GAD}^{-} / \mathrm{NGluT2}{ }^{+}$W/PS could be clearly measured $(n=4)$, the units increased their rate $338 \pm 83 \mathrm{~ms}$ before waking from SWS. They did so $1740 \pm 440$ ms before entry into full PS from SWS and tPS, thus during tPS, when the EEG progressively changes from prominent spindle $(\sim 9-14 \mathrm{~Hz})$ to rhythmic $\theta$ activity $(\sim 6-8 \mathrm{~Hz})$ accompanied by high amplitude $\gamma(30-60 \mathrm{~Hz})$ (Fig. $4 A-C)$. Across sleep-wake states, their discharge rate was significantly $(p<0.05$ per cell, $n=$ $5)$ and positively correlated with EEG $\gamma$ amplitude $(r=0.45 \pm$ $0.08)$ and $\theta$ activity $(\theta / \delta: r=0.65 \pm 0.13)$ and reciprocally negatively correlated with $\delta$ amplitude $(r=-0.47 \pm 0.07)$. They were all slow firing cells discharging in single spikes with either a tonic regular $(n=2)$ or irregular pattern $(n=4$; Table 1$)$. As for the cell shown in Figure 4, both their average discharge rate $(4.27 \pm 1.56 \mathrm{~Hz})$ and mean instantaneous firing frequency $(7.73 \pm 1.23 \mathrm{~Hz})$ were slow, reflecting a single spike, tonic mode of firing (Table 2; Figs. 3 and 4D). Their firing was found not to be rhythmic (examined by autocorrelation; Fig. 4E) nor crosscorrelated with fast or slow EEG activity (examined by spiketriggered averaging; Fig. $4 F$ ). They had, on average, a relatively long spike duration (1.65 $\pm 0.13 \mathrm{~ms}$; Table 2; Fig. 3$)$.

$\mathrm{Nb}^{+} / \mathrm{GAD}^{+}$, GABAergic neurons $(n=5)$ represented $17 \%$ of the W/PS-max active subgroup (Table 1). They discharged at significantly higher rates during aW and PS than during SWS. Although some (2 of 5) discharged at higher rates during aW than PS, most ( 3 of 5 ) discharged at their highest rates during PS, as illustrated by the cell in Figure 5 (CBS37U02). On average, their discharge rate was slow during aW $(5.52 \pm 2.59 \mathrm{~Hz})$, decreased during $\mathrm{qW}$ to reach minimal rates during tSWS and SWS $(0.22 \pm$ $0.13 \mathrm{~Hz}$ ), and then increased during tPS to reach maximal rates during PS $(9.30 \pm 4.06 \mathrm{~Hz}$ ) (Table 3; Fig. 5A-C). Their changes in discharge did not anticipate changes in cortical activation, as seen in the transition from SWS to W, when their discharge only increased after cortical activation occurred (by $570 \pm 20 \mathrm{~ms}$ on average in 4 units). On the other hand, most units increased their discharge during tPS before entry into full PS (Fig. 5A-C). Across sleep-wake states, their average discharge rate was significantly $(p<0.05$ per cell, $n=4)$ positively correlated with EEG $\gamma$ amplitude $(r=0.69 \pm 0.07)$ and $\theta$ activity $(\theta / \delta: r=0.71 \pm 0.09)$, whereas it was negatively correlated with $\delta$ amplitude $(r=$ $-0.64 \pm 0.04$ ). Most units ( 4 of 5 ) were fast spiking. Across all units, the mean instantaneous firing frequency $(55.68 \pm 16.66$ $\mathrm{Hz})$ was much higher than the average discharge rate $(12.17 \pm$ $3.55 \mathrm{~Hz}$ ) (Table 2; Figs. 3 and $5 D$ ) and reflected a phasic firing pattern of clusters $(n=2)$ or bursts $(n=2)$ of spikes or a tonic irregular pattern of single spikes $(n=1)$. As for the cell in Figure 4 , none of the units showed rhythmic firing (Fig. $5 E$ ) or crosscorrelated firing with slow or fast EEG activity (Fig. $5 F$ ). $\mathrm{Nb}^{+}$/ $\mathrm{GAD}^{+}$neurons had, on average, a relatively narrow spike width (1.00 $\pm 0.06 \mathrm{~ms}$; Table 2; Fig. 3 ).

\footnotetext{
$\leftarrow$

-max cell (right, shown in Fig. 6). The waveforms of the cholinergic and glutamatergic cells are similar, whereas that of the GABAergic cell is more narrow. $\boldsymbol{B}$, Average spike durations of the different cell types and subgroups (W/PS-max, red filled; PS-max, green filled; and W-max, red open symbols, as in Fig. 2). The VAChT ${ }^{+}$cells and $\mathrm{VAChT}^{-} / \mathrm{GAD}^{-}$cells, which have similarly medium to broad and overlapping spike durations, differ significantly from the $\mathrm{GAD}^{+}$cells (Table 2), which have narrow to medium spike durations. C, Average instantaneous firing frequency of the different cell types and subgroups. The mean instantaneous firing frequency of $\mathrm{VAChT}^{+}$cells was slow and differed significantly from the mean instantaneous firing frequency of congener W/PSGAD ${ }^{+}$cells but not from all GAD ${ }^{+}$or VAChT ${ }^{-} / \mathrm{GAD}^{-}$cells (Table 2) because of the extensive overlap in values. $\boldsymbol{D}$, Average discharge rate of the different cell types and subgroups. The mean average discharge rate of $\mathrm{VAChT}^{+}$cells was slow and did not differ significantly from the mean average discharge rate of $\mathrm{GAD}^{+}$or VAChT ${ }^{-} / \mathrm{GAD}^{-}$cells (Table 2) because of extensive overlap in values.
} 
Table 3. Average discharge rates of cholinergic, GABAergic, and noncholinergic/non-GABAergic, including identified glutamatergic, cell groups across sleep-wake stages ${ }^{a}$

\begin{tabular}{|c|c|c|c|c|c|c|c|}
\hline Cell type and subgroup & $n$ & $\mathrm{aW}$ & qW & tSWS & SWS & tPS & PS \\
\hline \multicolumn{8}{|l|}{$\mathrm{VAChT}^{+}$} \\
\hline $\begin{array}{l}\text { W/PS-max } \\
\mathrm{GAD}^{+}\end{array}$ & 6 & $2.28 \pm 1.31^{b}$ & $1.07 \pm 0.52$ & $0.24 \pm 0.09$ & $0.04 \pm 0.01$ & $0.71 \pm 0.48$ & $3.73 \pm 1.46^{b}$ \\
\hline W/PS-max & 5 & $5.52 \pm 2.59^{b}$ & $3.17 \pm 2.17$ & $0.27 \pm 0.15$ & $0.22 \pm 0.13$ & $1.26 \pm 0.71$ & $9.30 \pm 4.06^{b}$ \\
\hline PS-max & 4 & $4.02 \pm 0.10$ & $3.87 \pm 0.28$ & $4.26 \pm 0.59$ & $4.75 \pm 0.76$ & $9.01 \pm 1.35$ & $16.85 \pm 2.27^{b}$ \\
\hline \multicolumn{8}{|l|}{$\mathrm{VAChT}^{-} / \mathrm{GAD}^{-}$} \\
\hline W/PS-max & 18 & $4.03 \pm 1.17^{b}$ & $2.78 \pm 1.16$ & $1.57 \pm 0.57$ & $0.71 \pm 0.24$ & $3.4 \pm 0.89$ & $8.49 \pm 1.93^{b}$ \\
\hline PS-max & 12 & $1.75 \pm 0.64$ & $2.54 \pm 1.00$ & $3.22 \pm 1.14$ & $4.04 \pm 1.00$ & $8.64 \pm 1.84$ & $15.56 \pm 3.26^{b}$ \\
\hline $\begin{array}{l}\text { W-max } \\
\left(\text { VGluT2 }^{+}\right)\end{array}$ & 7 & $4.23 \pm 2.36^{b}$ & $2.53 \pm 1.48$ & $1.95 \pm 1.22$ & $1.57 \pm 0.97$ & $1.46 \pm 1.07$ & $0.38 \pm 0.18$ \\
\hline W/PS-max & (3) & $(1.54 \pm 1.18)^{b}$ & $(1.14 \pm 0.93)$ & $(1.07 \pm 1.01)$ & $(0.63 \pm 0.61)$ & $(2.12 \pm 1.79)$ & $(5.32 \pm 2.39)^{b}$ \\
\hline PS-max & (1) & $(0.13)$ & $(0.07)$ & $(0.30)$ & $(1.77)$ & $(7.2)$ & $(9.42)^{b}$ \\
\hline W-max & (2) & $(12.02 \pm 5.39)^{b}$ & $(7.99 \pm 2.01)$ & $(6.32 \pm 2.13)$ & $(5.00 \pm 1.83)$ & $(6.28 \pm 4.28)$ & $(0.97 \pm 0.19)$ \\
\hline
\end{tabular}

${ }^{a}$ Mean \pm SEM average discharge rate across sleep stages per sleep-wake subgroup of units classified according to state(s) of maximal discharge (with those rates marked as " $b$ "). A two-way ANOVA (cell type and stage) per sleep-wake subgroup was performed for the $\mathrm{VAChT}^{+}, \mathrm{GAD}^{+}$, and VAChT ${ }^{-} / \mathrm{GAD}^{-}$cell types. Although the discharge rate varied significantly as a function of sleep-wake stage for each subgroup, the average discharge rate did not vary significantly as a function of cell type $(p>0.05)$ or in the interaction between stage and cell type $(p>0.05)$ in any subgroup. The data for the VGluT2 ${ }^{+}$cells, which represent a subset of the VAChT ${ }^{-} /$GAD $^{-}$cells, are also presented in parentheses. In the W/PS-max subgroup, the VGluT2 ${ }^{+}$cells did not differ from the VAChT ${ }^{+}$or GAD ${ }^{+}$cells (in two-way ANOVA, as above), nor did they differ from the VAChT ${ }^{-} / \mathrm{GAD}^{-}$cells $(t$ test, $n=3$ and $n=15 ; p>0.05$ ).

$\mathrm{Nb}^{+} / \mathrm{VAChT}^{-} / \mathrm{GAD}^{-}$and $/ \mathrm{VGluT}^{+}$, possibly and identified glutamatergic, neurons $(n=18)$ represented $62 \%$ of the W/PS-max subgroup (Table 1). They discharged at significantly higher rates during aW and PS than during SWS. Some discharged at their highest rate during aW (4 of 18), whereas most (14 of 18) discharged at their highest rate during PS, as illustrated by the cell shown in Figure 6 (CBS51U01, which was also $\mathrm{VGluT}^{+}$; data not shown). Their mean average discharge rate was slow during aW $(4.03 \pm 1.17 \mathrm{~Hz})$, decreased during $\mathrm{qW}$ and tSWS to reach minimal rates during SWS $(0.71 \pm 0.24 \mathrm{~Hz})$, and then increased during tPS to reach the maximal average rate during PS $(8.49 \pm 1.93 \mathrm{~Hz})$ (Table 3; Fig. 6A-C). Most units increased their discharge rate before the cortical activation that occurred in transitions from SWS to W with a mean anticipation of $739 \pm 16 \mathrm{~ms}(n=9)$. Most also accelerated their discharge before PS, by a mean of $2008 \pm 440 \mathrm{~ms}(n=15)$, thus during tPS (Fig. $6 A-C$ ). Across sleep-wake states, their average discharge rate was significantly ( $p<0.05$ per cell, $n=12$ ) and positively correlated with EEG $\gamma$ amplitude $(r=0.45 \pm 0.04)$ and $\theta$ activity $(\theta / \delta: r=0.58 \pm 0.09)$, whereas it was inversely negatively correlated with $\delta$ amplitude $(r=-0.53 \pm 0.06)$. $\mathrm{VAChT}^{-} / \mathrm{GAD}^{-}$ (including VGluT2 ${ }^{+}$) W/PS-max cells were comprised by fast $(n=11)$ and slow firing cells $(n=7)$. Their mean instantaneous firing frequency was moderately high $(27.04 \pm 5.39 \mathrm{~Hz})$ and higher than the average discharge rate $(9.07 \pm 1.94 \mathrm{~Hz})$ (Table 2; Fig. 3), reflecting a phasic cluster firing pattern in many cells $(n=$ $6)$ in addition to tonic irregular $(n=8)$ and regular $(n=4)$ patterns in others. Neither fast nor slow firing units showed rhythmic firing, as examined by autocorrelation, or crosscorrelated firing with fast or slow EEG activity (Fig. $6 E, F$ ). They had, on average, a medium spike duration $(1.54 \pm 0.11 \mathrm{~ms}$; Table 2; Fig. 3). On none of the physiological parameters did the $\mathrm{VAChT}^{-} / \mathrm{GAD}^{-}$and the $\mathrm{VAChT}^{-} / \mathrm{GAD}^{-} / \mathrm{VGluT}^{+}{ }^{+} \mathrm{W} / \mathrm{PS}-\max$ cells differ significantly (Tables 2 and 3; Fig. 3).

\section{PS-max active neurons}

The PS-max active neurons represented the second most numerous subgroup found in the LDT, SubLDT, and MPPT area $(n=$ 16) and included $\mathrm{Nb}^{+} / \mathrm{GAD}^{+}$and $\mathrm{Nb}^{+} / \mathrm{VAChT}^{-} / \mathrm{GAD}^{-}$(with VGluT2 $^{+}$) cells. They discharged at minimal rates during $\mathrm{W}$ and maximal rates during PS.

$\mathrm{Nb}^{+} / \mathrm{GAD}^{+}$, GABAergic neurons $(n=4)$ represented $25 \%$ of the PS-max subgroup (Table 1). Some cells (2 of 4), as shown for the cell in Figure 7 (CBS28U04, also shown as $\mathrm{GAD}^{+}$in Fig. 1A), increased their discharge rate progressively from the minimum during aW through qW, tSWS, SWS, and tPS to reach their maximum during PS, whereas others ( 2 of 4 ) only markedly increased their rate during tPS, immediately preceding PS. For the subgroup, the mean discharge was lowest during aW $(4.02 \pm 0.10$ $\mathrm{Hz})$, slightly higher during SWS $(4.75 \pm 0.76 \mathrm{~Hz})$, and much higher during PS $(16.85 \pm 2.27 \mathrm{~Hz})$ (Table 3). Cells increased their rate of firing in anticipation of PS by an average of $2350 \pm$ $11.3 \mathrm{~ms}$ and thus most markedly during tPS $(n=4)$ (Fig. $7 A-C)$. Their average discharge rate varied in an inverse manner to EMG amplitude with which it was significantly ( $p<0.05$ per cell, $n=$ $2)$ negatively correlated across sleep-wake states $(r=-0.52 \pm$ 0.07 ) (Fig. 7). It was also significantly ( $p<0.05$ per cell, $n=4)$ positively correlated with EEG $\gamma(r=0.34 \pm 0.01)$ and $\theta$ activity $(\theta / \delta: r=0.52 \pm 0.09)$ while being negatively correlated with $\delta$ $(r=-0.43 \pm 0.16)$. All $\mathrm{GAD}^{+}$cells were fast firing, and their mean instantaneous firing frequency $(38.13 \pm 13.63 \mathrm{~Hz})$ was higher than their average discharge rate $(16.85 \pm 2.27 \mathrm{~Hz}$; Table 2; Figs. 3 and $7 C, D)$, reflecting a phasic cluster firing pattern $(n=$ 1) or a tonic irregular $(n=2)$ in addition to a tonic regular firing pattern $(n=1)$. In one cell, shown in Figure 7, the phasic cluster pattern of firing was rhythmic and cross-correlated with $\theta$ activity (at $6 \mathrm{~Hz}$ ) during PS (Fig. $7 E, F$ ). In no other cells was the unit firing rhythmic or cross-correlated with slow or fast EEG activity. They had, on average, a relatively narrow spike width (0.96 \pm 0.09 ms; Table 2; Fig. 3).

$\mathrm{Nb}^{+} / \mathrm{VAChT}^{-} / \mathrm{GAD}^{-}$and /VGluT2 ${ }^{+}$, possibly and identified glutamatergic, neurons $(n=12)$ represented $75 \%$ of the PS-max subgroup (Table 1). As characteristic of PS-max cells, they discharged at their lowest rate during aW $(1.75 \pm 0.64 \mathrm{~Hz})$, a higher rate during SWS $(4.04 \pm 1.00 \mathrm{~Hz})$, and maximal rate during PS (15.56 $\pm 3.26 \mathrm{~Hz}$, Table 3). Some (5 of 12), as shown for the cell in Figure 8 (CBS46U02, which was also VGluT2 ${ }^{+}$; data not shown), progressively increased their rate from aW to SWS, whereas others (7 of 12) only markedly increased their rate during tPS, immediately preceding PS. Almost all units accelerated their discharge before PS, by on average $3420 \pm 780 \mathrm{~ms}$ ( $n=$ 10 ) and thus most markedly during tPS (Fig. $8 A-C$ ). Their average discharge rate varied inversely with EMG amplitude with which it was significantly ( $p<0.05$ per cell, $n=4$ ), negatively correlated across sleep-wake states $(r=-0.44 \pm 0.08)$. It was also significantly ( $p<0.05$ per cell, $n=7$ ), positively correlated with EEG $\gamma(r=0.57 \pm 0.07)$ and $\theta$ activity $(\theta / \delta: r=0.59 \pm 0.15)$ while being negatively correlated with $\delta$ activity $(r=-0.38 \pm$ 


\section{W/PS-max: $\mathrm{Nb}+\mathrm{VAChT}+$ neuron (\#CBS28U03)}

A
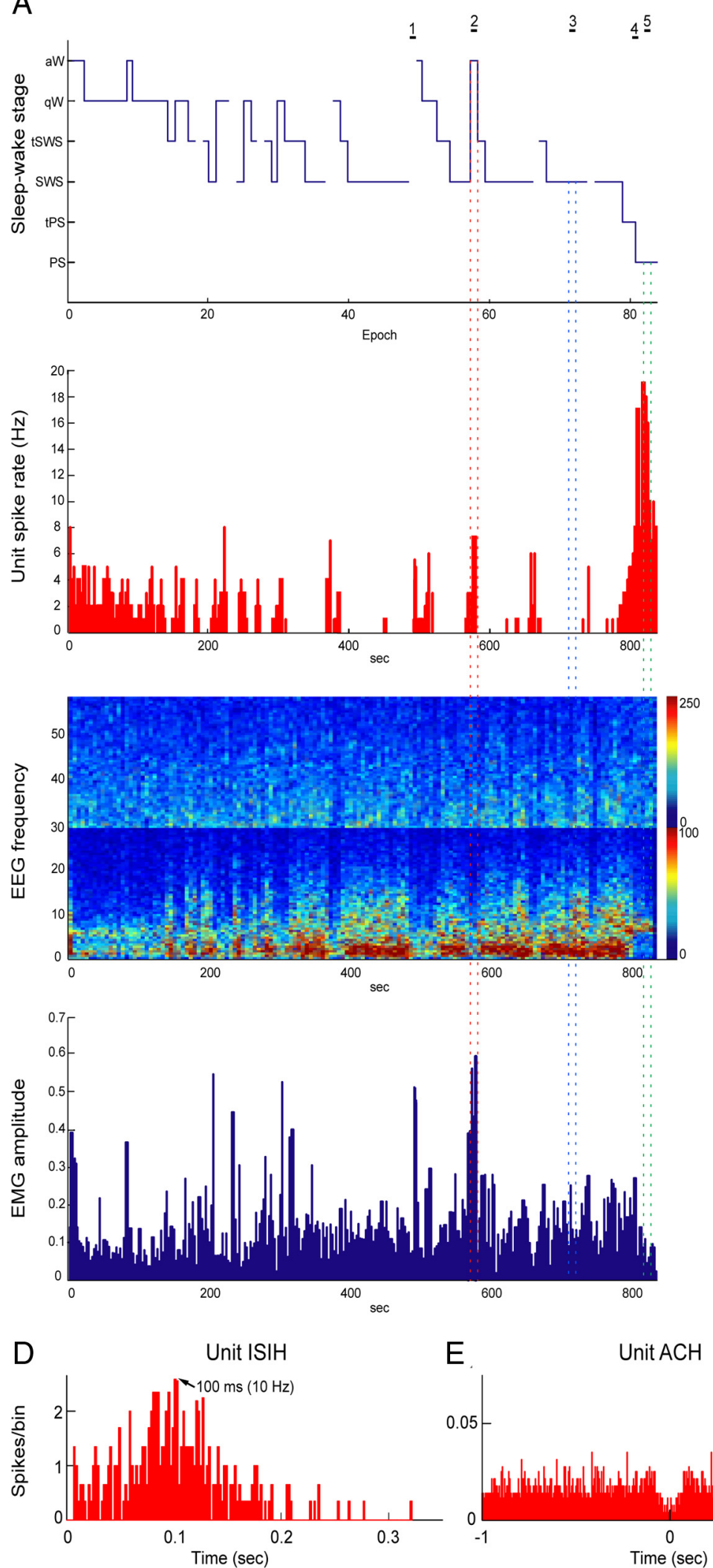

$E$

Unit $\mathrm{ACH}$

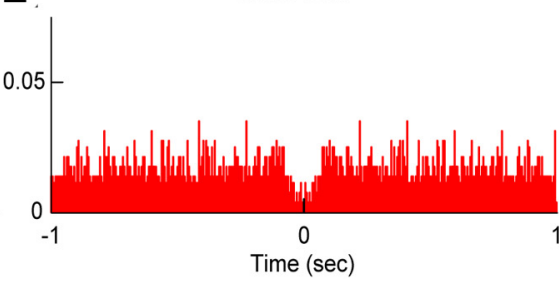

SWS

aW

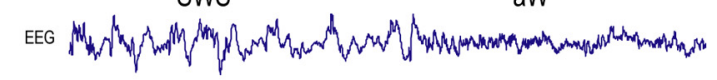

1 EMG

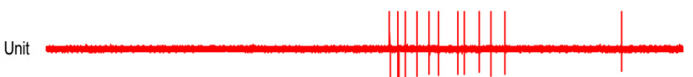

aW

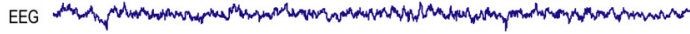

2 EMG

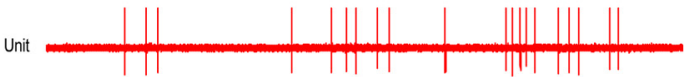

SWS

$3 \mathrm{EMG}$

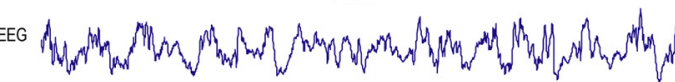

Unit

tPS

PS

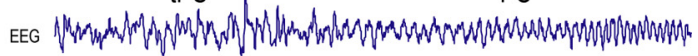

4 EMG

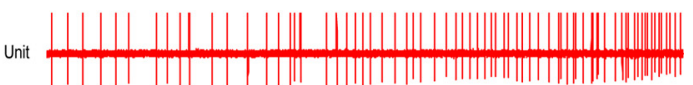

PS

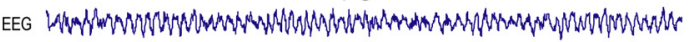
5 EMG

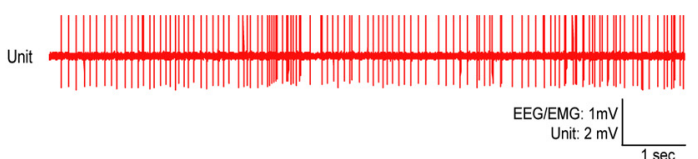

C
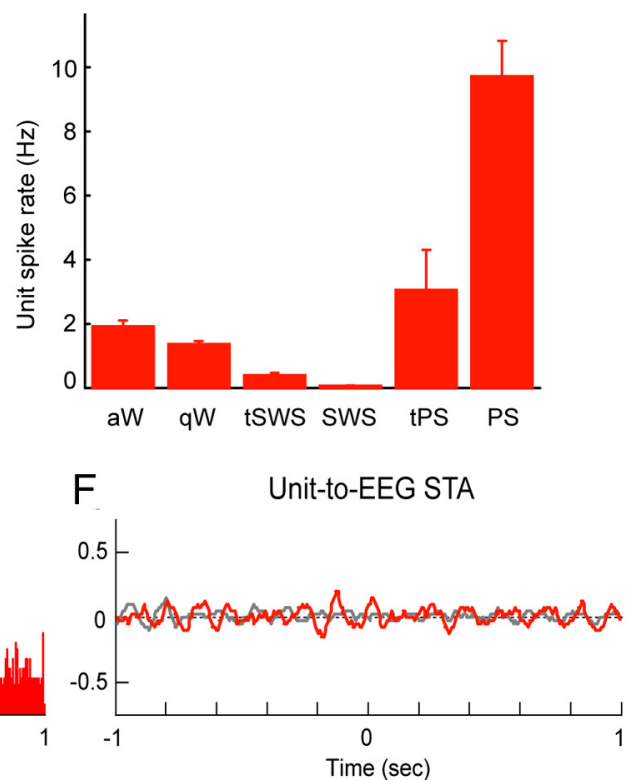

Figure 4. Discharge of cholinergic W/PS-max active unit across sleep-wake states. Data from Nb-labeled cell (CBS28U03) that was immunopositive for VAChT (Fig. 1A1-A3) and located in the LDT (Fig. 2, A0.5). A, Sleep-wake recording, scored (per 10 s epoch) for sleep-wake stages, is shown with simultaneous unit spike rate (Hz), EEG frequency, and amplitude ( $\mu \mathrm{V} / \mathrm{Hz}$ with frequency on $y$-axis and amplitude scaled differentially according to color from blue to red, over the low-frequency, $0-30 \mathrm{~Hz}$ from 0 to $100 \mu \mathrm{V}$, and the high-frequency, $30-60 \mathrm{~Hz}$ from 0 to $25 \mu \mathrm{V}$ ) and EMG amplitude (arbitrary units) over the recording session. Representative $10 \mathrm{~s}$ scored epochs (indicated by horizontal solid lines and dashed vertical lines) of aW (red), (Figure legend continues.) 
0.13). Most $\mathrm{VAChT}^{-} / \mathrm{GAD}^{-}$PS-max cells (10 of 12) were fast spiking. Their mean instantaneous firing frequency (76.32 \pm $20.40 \mathrm{~Hz}$ ) was much higher than the average discharge rate (15.56 $\pm 3.26 \mathrm{~Hz}$; Table 2; Fig. 3), reflecting the predominance of phasically cluster $(n=4)$ or burst $(n=4)$ firing neurons (Fig. $8 D)$ in addition to tonic irregular $(n=1)$ and regular $(n=3)$ firing neurons. None of these units showed rhythmicity in their firing or cross-correlation with EEG activity (Fig. 8E,F). They had, on average, a medium spike width ( $1.27 \pm 0.09 \mathrm{~ms}$; Table 2; Fig. 3$)$. The one VGluT2 ${ }^{+}$cell fell within the distribution of the $\mathrm{VAChT}^{-} / \mathrm{GAD}^{-}$cells on all physiological parameters (Tables 2 and 3; Fig. 3).

\section{W-max active neurons}

$\mathrm{W}$-max active neurons represented the smallest subgroup in the LDT, SubLDT, and MPPT areas $(n=7)$. This subgroup comprised only $\mathrm{VAChT}^{-} / \mathrm{GAD}^{-}$along with $\mathrm{VGluT2}^{+}$cells. As shown for the cell in Figure 9 (CBS47U02, also shown as VGluT2 $^{+}$in Fig. $1 B$ ), the cells discharged at their highest rates during aW $(4.23 \pm 2.36 \mathrm{~Hz})$ and decreased their firing during $\mathrm{qW}, \mathrm{tSWS}$, and SWS $(1.57 \pm 0.97 \mathrm{~Hz})$ and tPS to reach their lowest rate during PS $(0.38 \pm 0.18 \mathrm{~Hz}$; Table 3$)$. The majority accelerated their discharge before transition to W from SWS by an average of $638 \pm 14 \mathrm{~ms}(n=5)$ (Fig. 9A-C). Their average discharge rate varied in a parallel manner with EMG amplitude with which it was significantly ( $p<0.05$ per cell, $n=4)$, positively correlated across sleep-wake states $(r=0.45 \pm 0.08)$. In contrast, their discharge rate was not consistently or significantly correlated with EEG $\gamma$ or $\theta$ activity. Most units ( 5 of 7 ) were slow firing neurons. Both their average discharge rate $(4.23 \pm 2.36 \mathrm{~Hz})$ and mean instantaneous firing frequency $(10.10 \pm 3.35 \mathrm{~Hz})$ were slow (Fig. 9C,D), reflecting their predominantly single spike tonic mode of firing in a regular $(n=2)$ or irregular $(n=4)$ pattern, in addition to one cluster pattern (Table 2; Fig. 3). Their firing was neither rhythmic nor cross-correlated with EEG activity (Fig. $9 E, F)$. They had, on average, a relatively long spike duration $\left(1.81 \pm 0.20 \mathrm{~ms}\right.$; Table 2; Fig. 3). The two VGluT2 ${ }^{+}$cells fell within the distribution of the $\mathrm{VAChT}^{-} / \mathrm{GAD}^{-}$cells on all physiological parameters (Tables 2 and 3; Fig. 3).

\footnotetext{
$\leftarrow$

(Figure legend continued.) SWS (blue), and PS (green) or transitional 10 s periods (lower solid horizontal lines) are shown in $\boldsymbol{B}$. The interruptions in the sleep-wake scoring line represent epochs during which transitions between stages occurred, such that no one stage was predominant and could thus be scored for analysis. $B$, Polygraphic records from 10 s epochs or periods (indicated by numbered horizontal lines in $\boldsymbol{A}$ ) of the unit together with EEG (from retrosplenial cortex) and EMG activity during a transition from SWS to aW (1), aW (2), SWS (3), a transition from tPS to PS (4), and PS (5). C, Bar graph showing mean spike rate $(\mathrm{Hz})$ of the unit across sleep-wake stages. During aW (2), the unit discharged tonically at a slow rate $(1.91 \mathrm{~Hz})$ with prominence of fast EEG activity, ceased firing during SWS (3) $(0.06 \mathrm{~Hz})$ in association with slow EEG activity $(\sim 1-4 \mathrm{~Hz})$ and discharged maximally and tonically to reach its highest rates during $\mathrm{PS}(5)(9.70 \mathrm{~Hz})$ in association with prominent rhythmic $\theta$ $(\sim 6-8 \mathrm{~Hz})$ along with fast EEG activity. It changed its rate of discharge before cortical activation in the transition from SWS to aW (1) and before PS during IPS (4) while spindle activity $(\sim 9-14 \mathrm{~Hz}$ ) progresses to $\theta$. The unit discharge was significantly positively correlated with EEG $\gamma(r=0.37)$ along with $\theta$ activity $(r=0.93)$. D , Unit ISIH from which the instantaneous firing frequency is calculated (as the reciprocal of the mode) for the state of maximal discharge. $\boldsymbol{E}$, Unit autocorrelation histogram ( $\mathrm{ACH}$ with arbitrary voltage units for spikes on vertical axes) for the state of maximal discharge. $\boldsymbol{F}$, Unit-to-EEG spike-triggered average (STA with mV EEG on vertical axes) for the state of maximal discharge with comparison of the actual unit spike train (red line) with a randomized shuffled spike train (gray line). This $\mathrm{VAChT}^{+}$cell, which discharged maximally during PS, fired in single spikes at a relatively slow instantaneous frequency $(10 \mathrm{~Hz}$, in ISIH) and in a relatively regular tonic mode, with no evidence of rhythmic firing (in $\mathrm{ACH}$ ) or crosscorrelated activity with slow or fast EEG rhythms (in STA).
}

\section{Comparison across sleep-wake subgroups}

Within each sleep-wake subgroup, the different neurotransmitter cell types showed similar profiles of discharge, as according to their classification (Fig. 10). For the W/PS-max subgroup, the profile of discharge rates across sleep-wake stages was very similar to the profile of EEG $\gamma$ activity $(30.5-58 \mathrm{~Hz}$ ) (Maloney et al., 1997) (Fig. 10A), with which the rates were commonly positively correlated while also being positively correlated with $\theta$ activity (as the ratio of $\theta(4.5-8.5 \mathrm{~Hz})$ over $\delta$; data not shown) and inversely negatively correlated with $\delta(1.0-4.5 \mathrm{~Hz}$; data not shown $)$. The unit firing was not significantly correlated with $\sigma(9.0-14.0 \mathrm{~Hz})$, $\beta 1$ (14.5-18.5 Hz), or $\beta 2(19.0-30.0 \mathrm{~Hz})$ activities. On the other hand, the firing of none of the W/PS cell types was crosscorrelated with high- or low-frequency EEG activity, including $\gamma$ and $\theta$ activity. The average discharge rates did not differ significantly between the cholinergic, GABAergic, and possibly or identified glutamatergic neurons across the three major states or six stages (Tables 2 and 3). Nonetheless, the cholinergic cells were all slow spiking neurons and discharged in a single spike, tonic, either regular or irregular, pattern, whereas the majority of the GABAergic and glutamatergic neurons were fast spiking and often discharged in phasic cluster or burst modes, although never rhythmically. Accordingly, the instantaneous firing frequency of the cholinergic neurons was significantly lower than that of the GABAergic neurons yet not significantly lower than that of the possibly or identified glutamatergic cells. The variability in firing by the latter was such that they could not be distinguished from either the cholinergic or GABAergic W/PS neurons (Table 2; Fig. $3)$. Similarly, for the mean spike duration, the cholinergic differed significantly from the GABAergic, whereas the possibly or identified glutamatergic differed significantly from neither the cholinergic nor the GABAergic (Table 2; Fig. 3).

For the PS-max subgroup, the GABAergic and the possibly or identified glutamatergic neurons also showed similar profiles of discharge across the sleep-wake stages and states (Fig. 10B; Table 3 ). The profile of discharge of both types across stages most resembled the inverse profile of EMG amplitude changes, with which the discharge rate was negatively correlated (Fig. 10B). It was also positively correlated with $\gamma$ and $\theta$ activity, which are maximal during PS (data not shown). The two cell types of this subgroup did not show any significant differences in their mean spike duration, average discharge rate, or instantaneous firing frequency, both tending to have narrow spikes and be fast spiking with a phasically modulated firing pattern (Table 2; Fig. 3). Except for one GABAergic cell (Fig. 7), none of the PS-max cells showed rhythmicity or cross-correlation with EEG in their firing.

Showing a reciprocal profile of discharge to the PS-max cells, the profile of the possibly and identified glutamatergic $\mathrm{W}$-max cells across sleep-wake stages most resembled the profile of EMG amplitude (Fig. 10C), with which it was positively correlated. They were predominantly tonically spiking cells with medium to broad spikes (Table 2; Fig. 3).

\section{Discussion}

Here we show, for the first time, that identified cholinergic neurons in the LDT, SubLDT, and MPPT discharge maximally during W and PS. Moreover, we show that codistributed GABAergic and glutamatergic neurons similarly discharge maximally during $\mathrm{W}$ and PS, or during PS or during W, in profiles once thought to signify cholinergic or monoaminergic neurons.

Many attempts have been made over the past 25 years in cats, rats, and mice to characterize the discharge of pontomesencephalic cholinergic neurons, some using waveform charac- 


\section{W/PS-max: Nb+/GAD+ neuron (\#CBS37U02)}
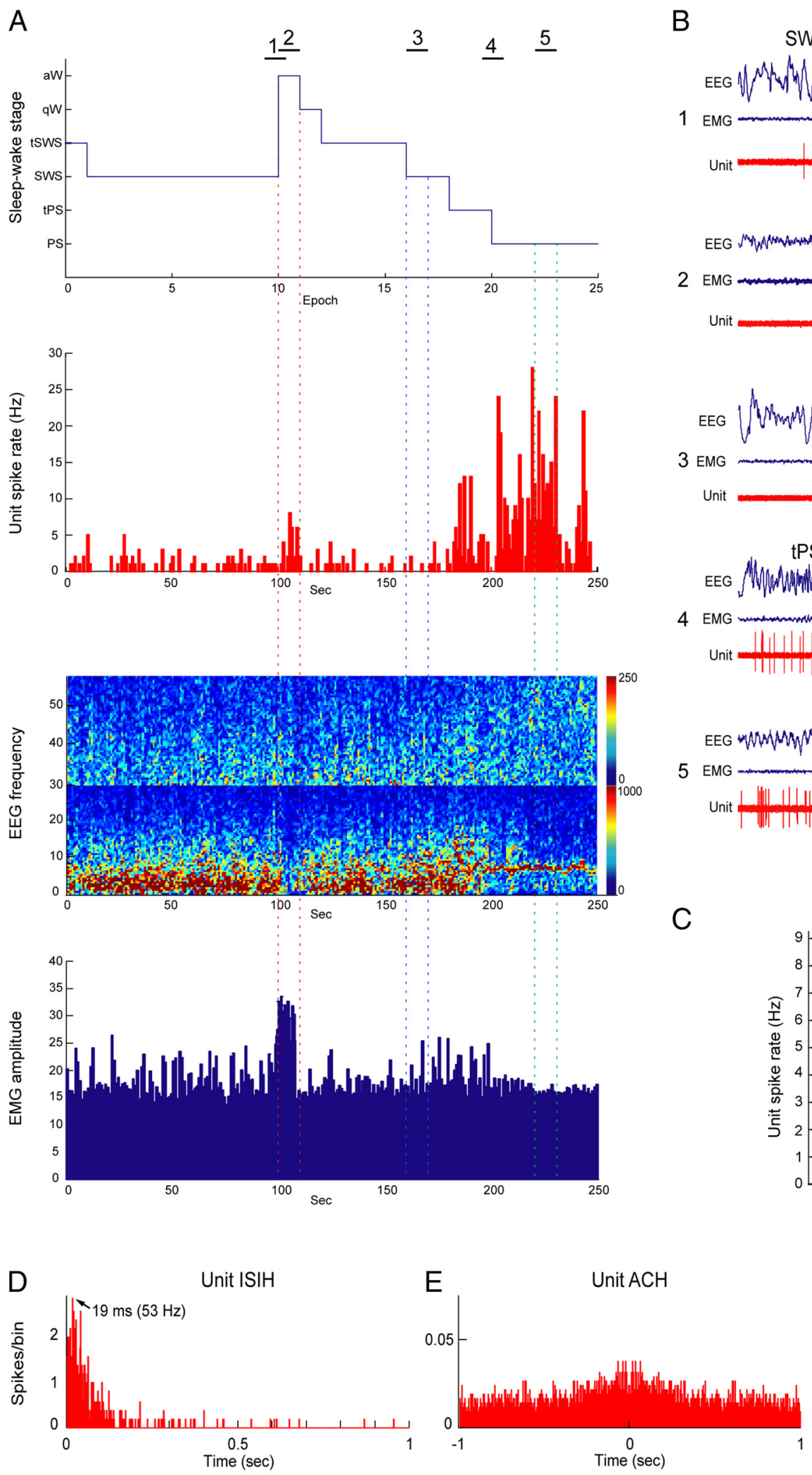
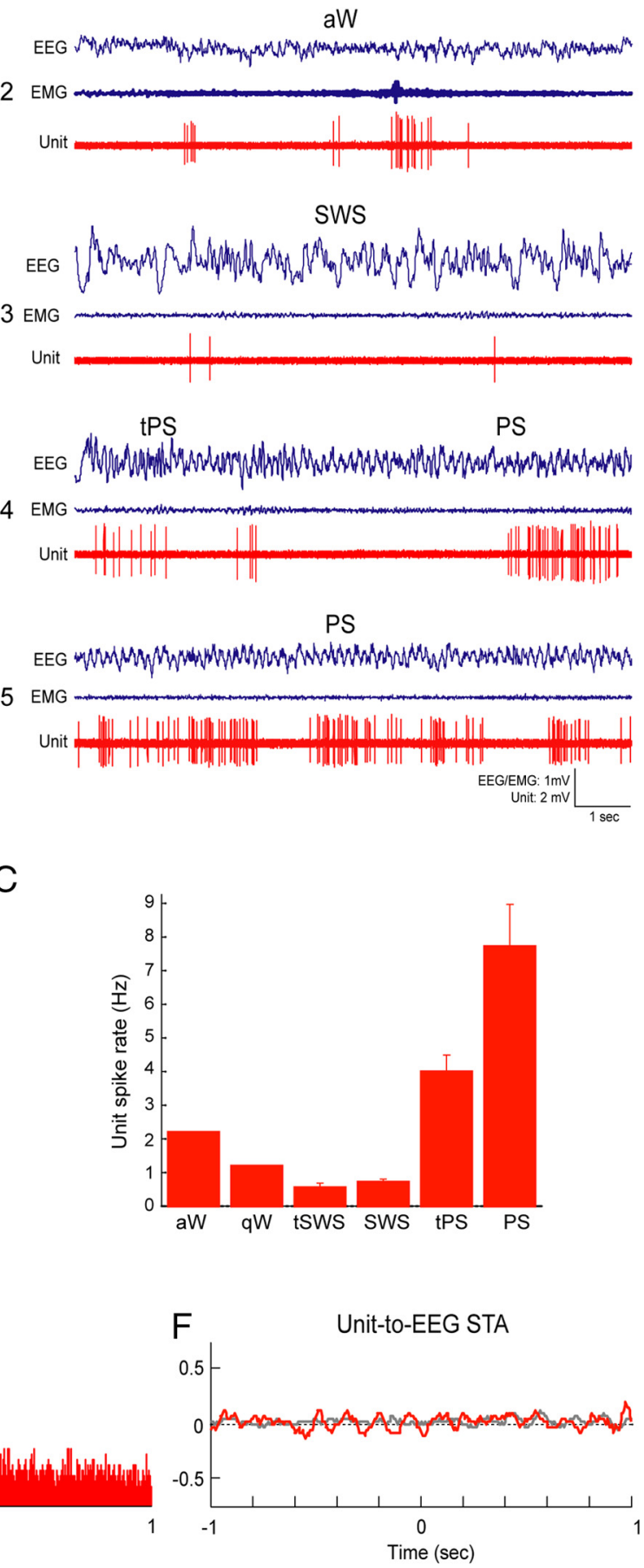

SWS

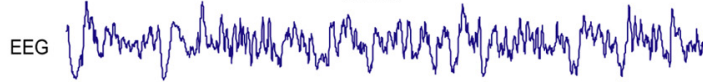

3 EMG

Unit

tPS

PS

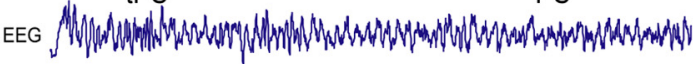

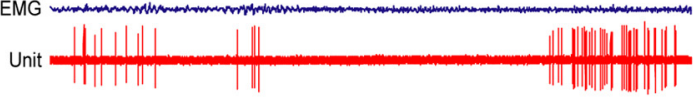

PS

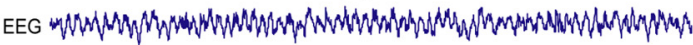

5

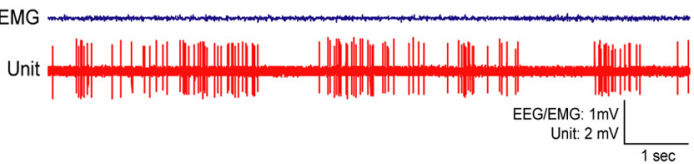

C

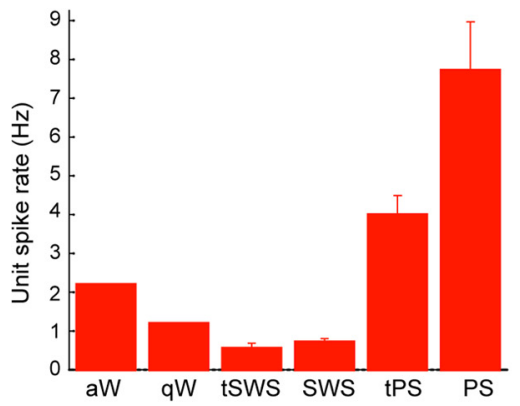

Figure 5. Discharge of GABAergic W/PS-max active unit across sleep-wake states. Data from Nb-labeled cell (CBS37U02) that was immunopositive for GAD (data not shown) and located in the SubLDT (Fig. 2, A0.1). A-C, This GAD ${ }^{+}$cell discharged moderately during aW (2) $(2.20 \mathrm{~Hz})$, minimally during SWS (3) $(0.72 \mathrm{~Hz})$ and maximally during PS (5) (7.72 Hz) in a phasic manner comprised of clusters of spikes. It changed its rate of discharge only after cortical activation in the transition from SWS to aW (1) but increased its rate before PS during tPS (4). The unit discharge was significantly positively correlated with EEG $\gamma(r=0.72)$ and $\theta$ activity $(r=0.90)$. $\mathbf{D}-\mathbf{F}$, During the state of maximal discharge (PS), the instantaneous firing frequency $(53 \mathrm{~Hz}$, in the ISIH) was much higher than the average discharge rate and reflected a phasic firing pattern in clusters, which however was neither rhythmic (in ACH) nor cross-correlated with slow or fast EEG rhythms (in STA). For details and abbreviations, see Figure 4. 


\section{W/PS-max: Nb+/VGluT2+ neuron (\#CBS51U01)}

A
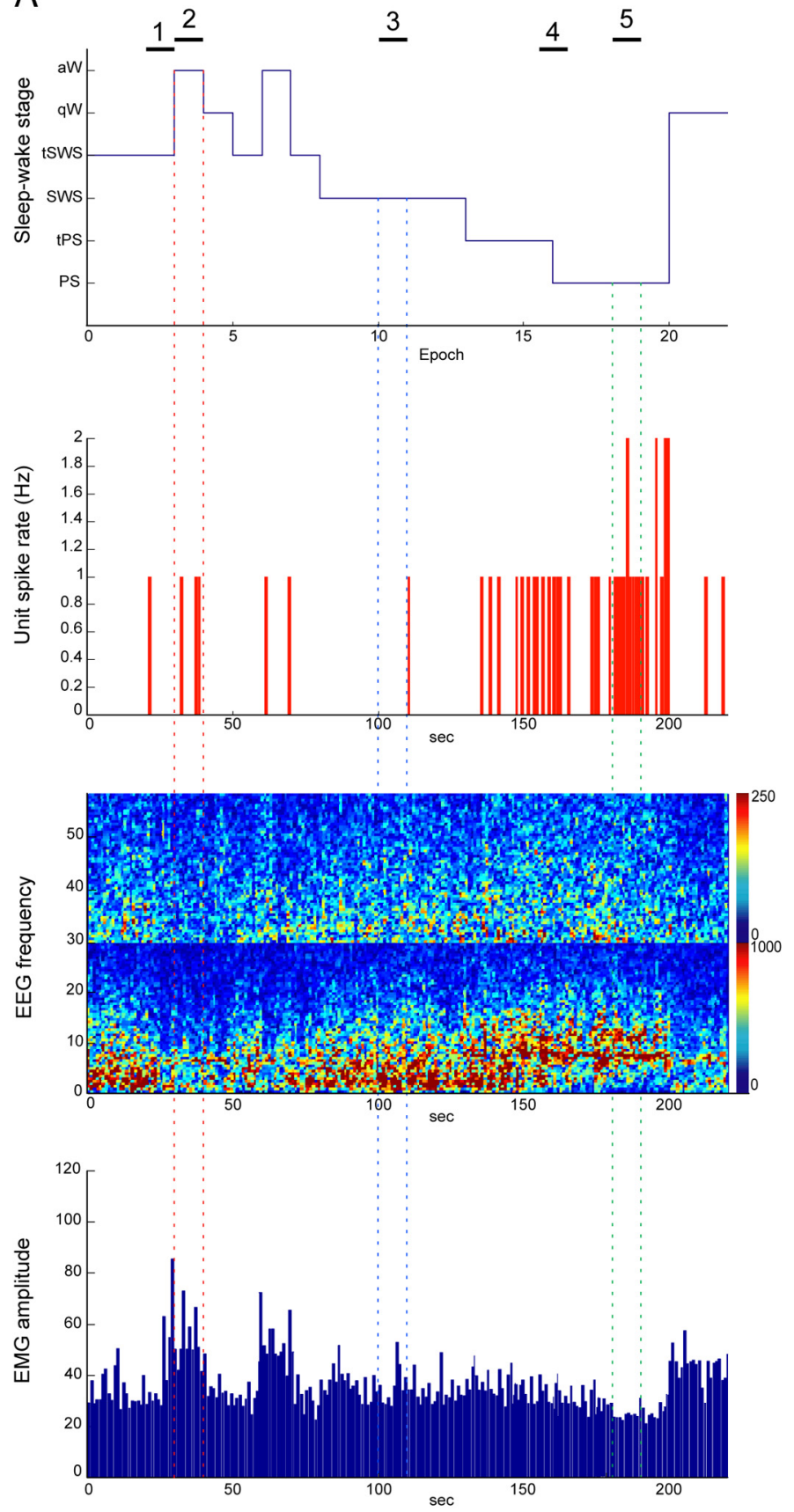

B

tSWS

$\mathrm{aW}$

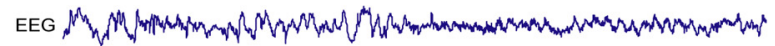

1 EMG

Unit

aW

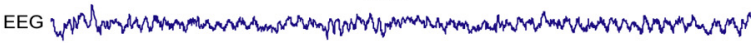

2 EM

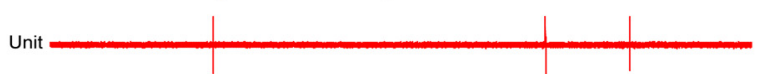

SWS

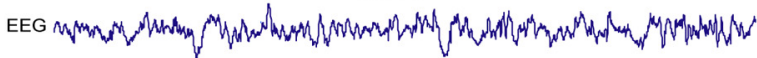
3 EMG

Unit

tPS

PS

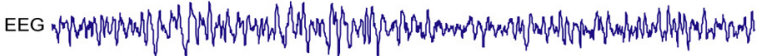
4 EMG

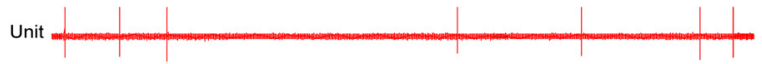

PS

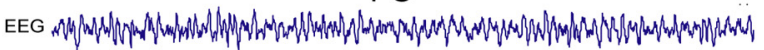
5 EмG

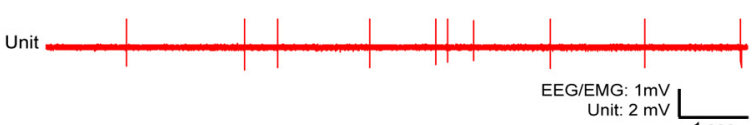

C

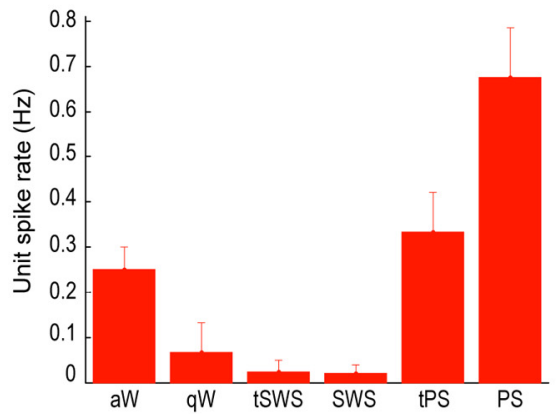

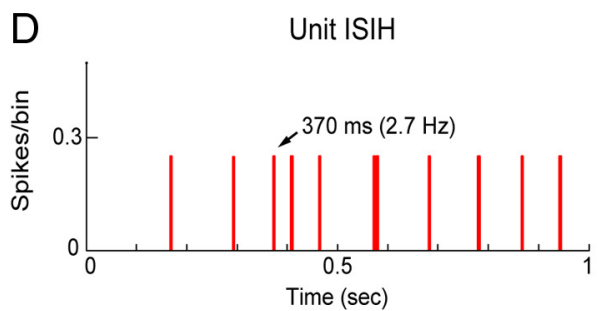
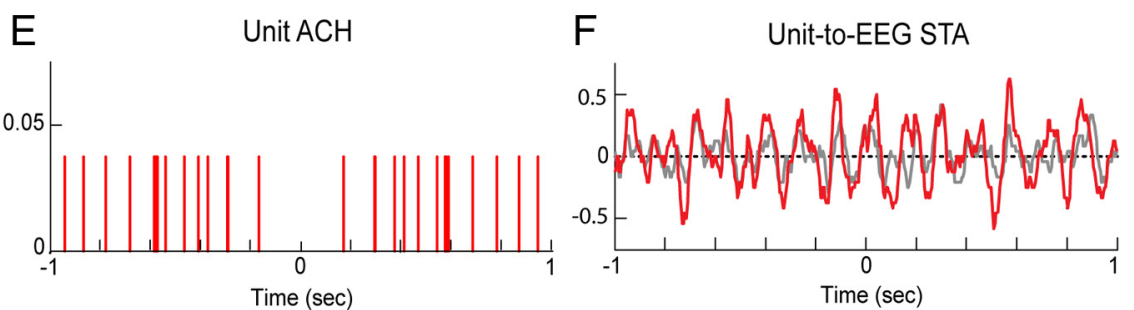

Figure 6. Discharge of glutamatergic W/PS-max active unit across sleep-wake states. Data from Nb-labeled cell (CBS51U01) that expressed VGluT2 (data not shown) and was located in the LDT (Fig. 2, A0.1). A-C, This VGluT2 ${ }^{+}$cell, discharged slowly during epochs of aW (2) $(0.25 \mathrm{~Hz})$, was virtually silent during SWS (3) $(0.02 \mathrm{~Hz})$ associated with slow EEG activity and discharged at its maximal, albeit slow, rate during PS (5) $(0.68 \mathrm{~Hz})$ in association with prominent $\theta$ and fast EEG activity. Slow firing, this cell did not appear to increase its rate of discharge before cortical activation in the transition from SWS to aW (1) but did begin to fire before PS during tPS (4). The unit discharge was significantly positively correlated with EEG $\gamma(r=0.34)$ and $\theta$ activity $(r=0.86)$. $\boldsymbol{D}-\boldsymbol{F}$, During the state of maximal discharge (PS), the instantaneous firing frequency (2.7 Hz in the ISIH) did not differ much from the average discharge rate, reflecting the tonic regular firing pattern, which was neither rhythmic (in ACH) nor cross-correlated with slow or fast EEG rhythms (in STA). For details and abbreviations, see Figure 4. 
PS-max: $\mathrm{Nb}+/ \mathrm{GAD}+$ neuron (\#CBS28U04)

A
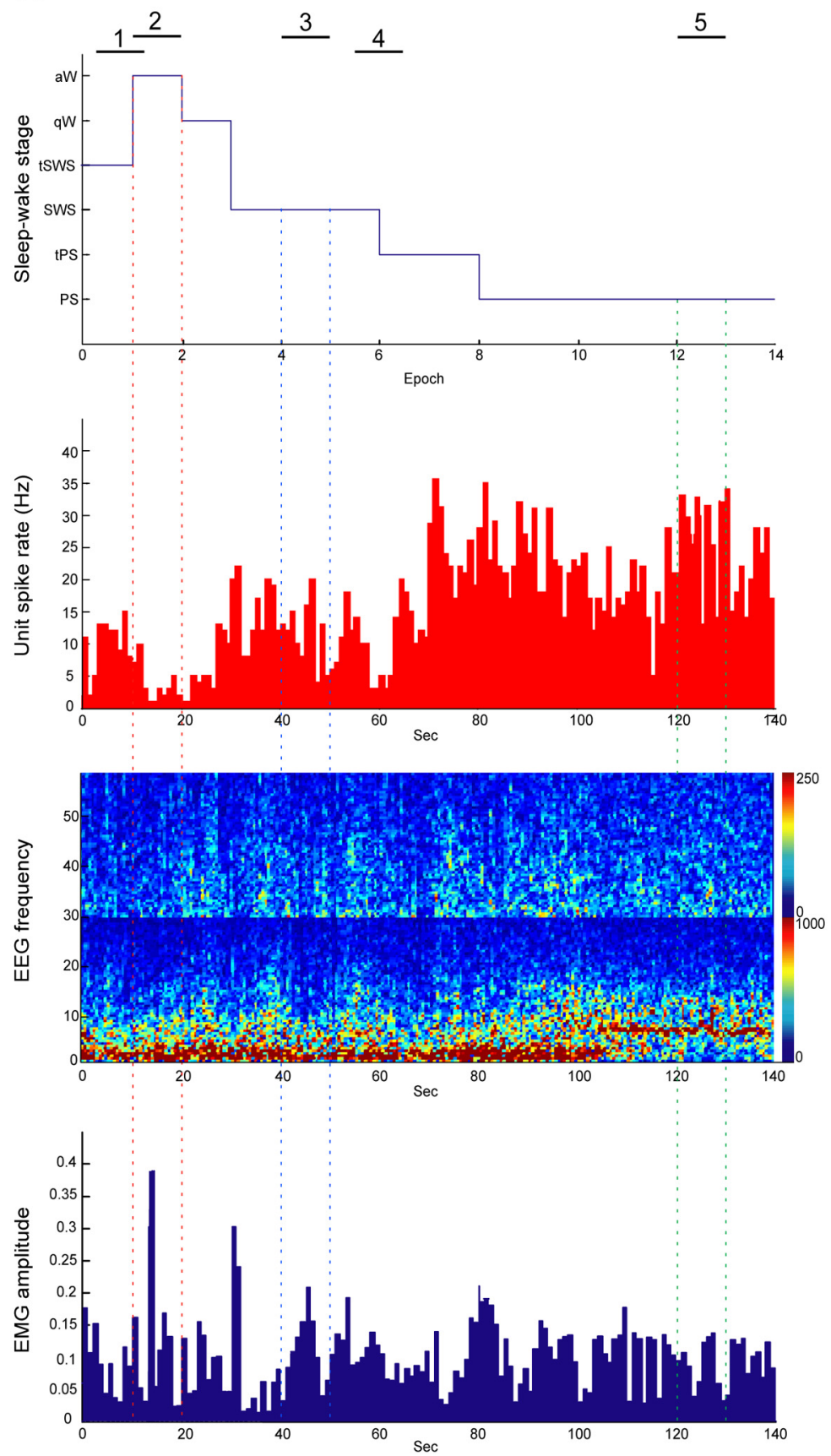

D
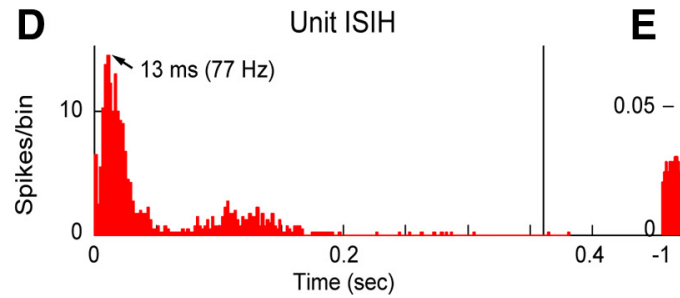

B

SWS

aW

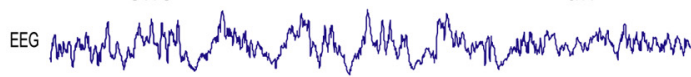

1 EMG

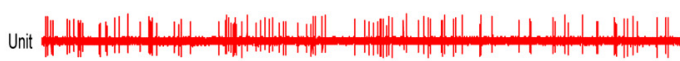

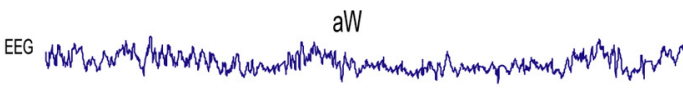

2 EMG

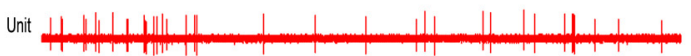

SWS

3 EMG

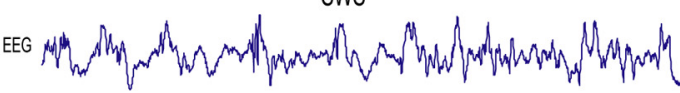

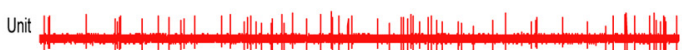

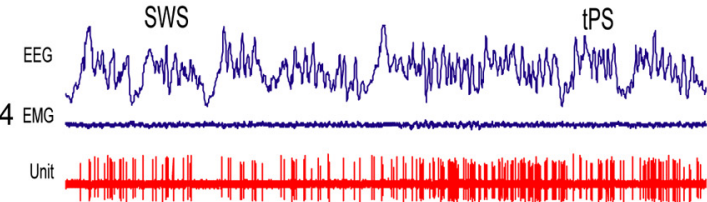

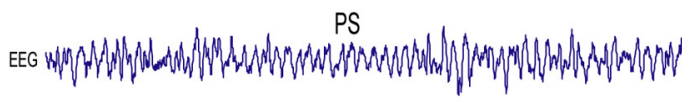
5 EMG

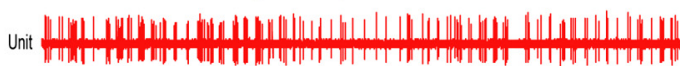

EEGIEMG: $1 \mathrm{mV}$
Unit: $2 \mathrm{mV}$

C

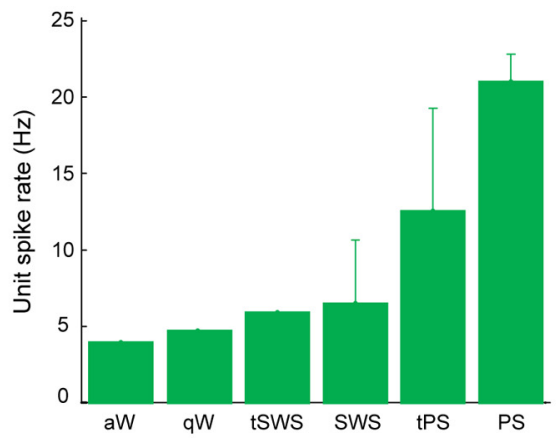

$\mathbf{F}$

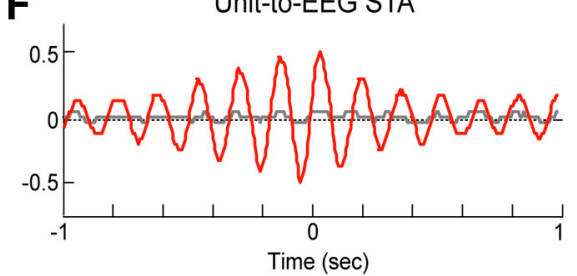

Figure 7. Discharge of GABAergic PS-max active unit across sleep-wake states. Data from Nb-labeled cell (CBS28U04) that was immunostained for GAD (Fig. 1A4-A6) and located in the SubLDT (Fig. 2, A0.1).A-C, This GAD ${ }^{+}$cell discharged at relatively low rates during aW (2) (3.90 Hz) with fastEEG activity and high EMG amplitude, increased firing during SWS (3) (6.05 Hz) in association with slow $\delta \mathrm{EEG}$ activity and low muscle EMG and discharged maximally during PS (5) $(20.98 \mathrm{~Hz})$ with $\theta$ and fast EEG activity accompanied by muscle atonia. It increased its discharge most markedly immediately preceding PS during tPS (4). The unit discharge was positively correlated with EEG $\theta$ activity $(r=0.53)$ and negatively correlated with EMG amplitude $(r=-0.45)$. D-F, During the state of maximal discharge (PS), there are two interspike interval modes (in the unit ISIH): one reflecting the high instantaneous firing frequency $(\sim 77 \mathrm{~Hz})$ during phasic spike clusters and the other, the slow rhythmic recurrence of the spike clusters. These spike clusters appear to be rhythmic at a $\theta$ frequency (in the $\mathrm{ACH}, \sim 6 \mathrm{~Hz}$ ) and cross-correlated with the EEG (in the STA) at the same frequency. For details and abbreviations, see Figure 4. 


\section{PS-max: $\mathrm{Nb+/VGluT2+} \mathrm{neuron} \mathrm{( \# CBS46U02)}$}

A
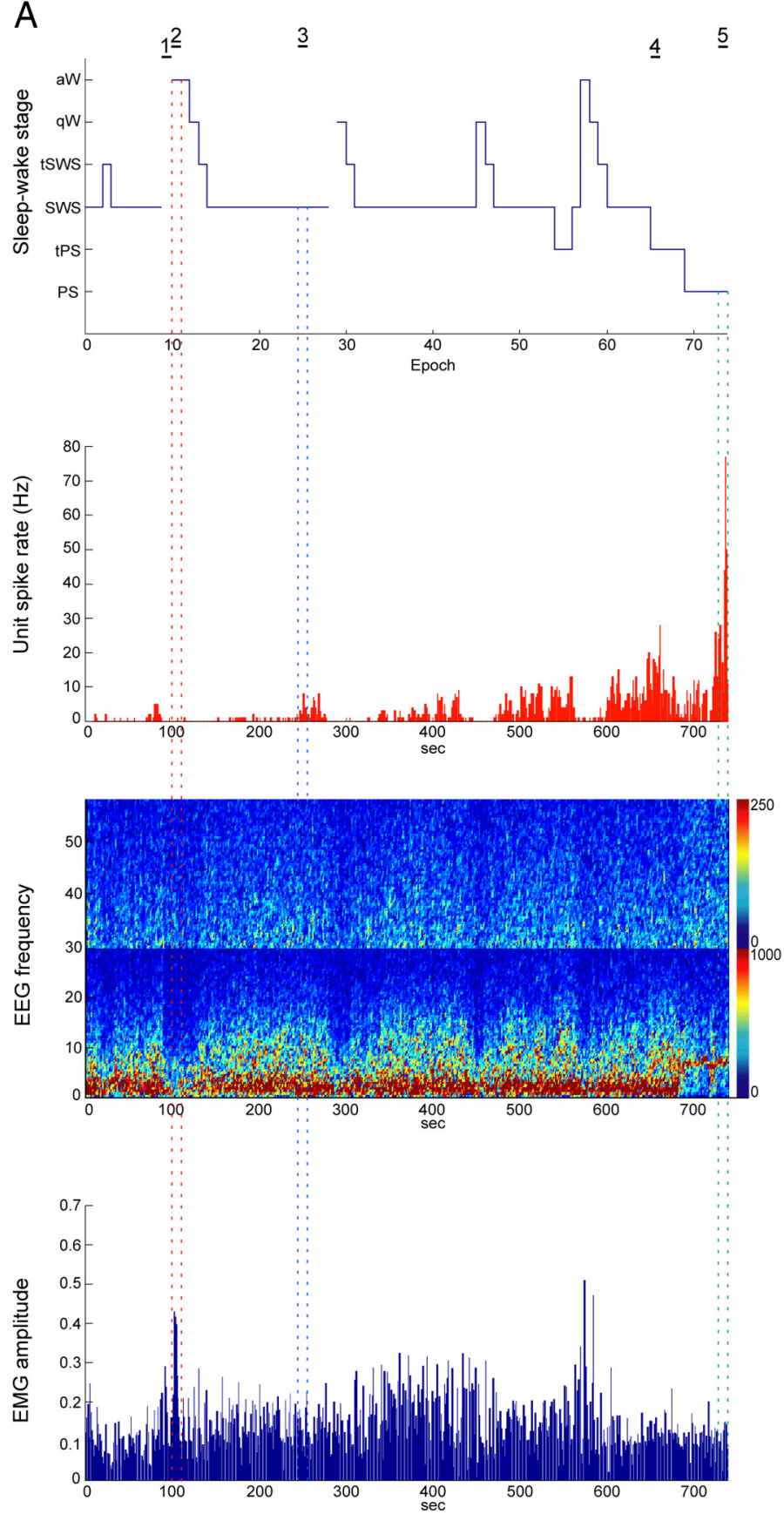

B

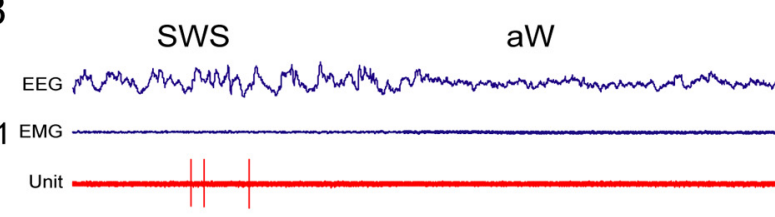

aW

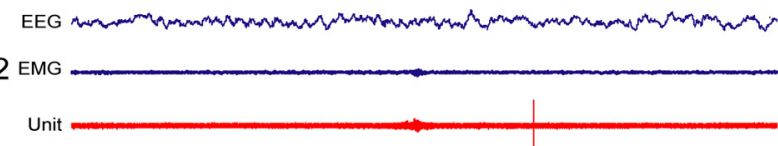

SWS

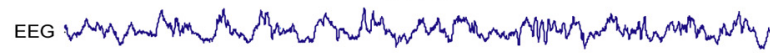
3 EMG

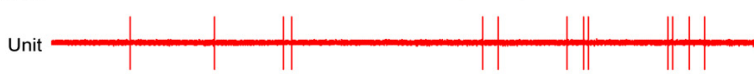

tPS

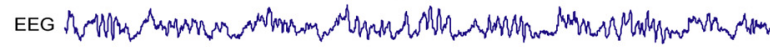
4 EMG

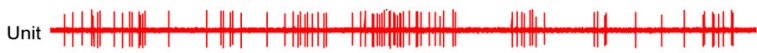

PS

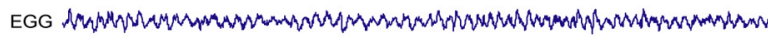
5 EMG

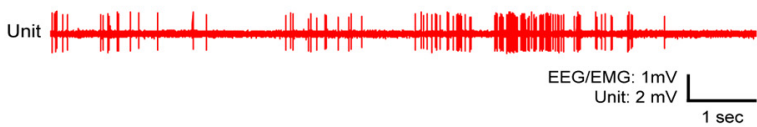

C

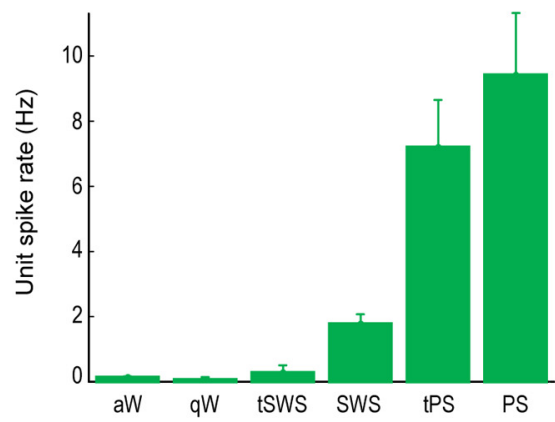

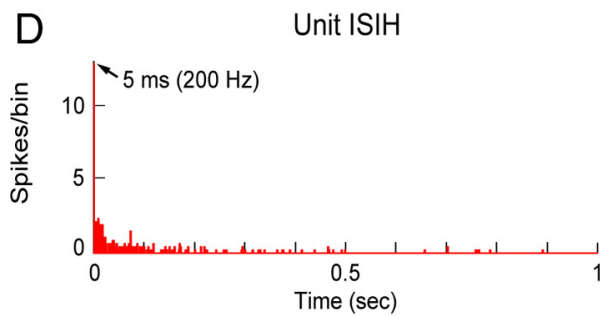

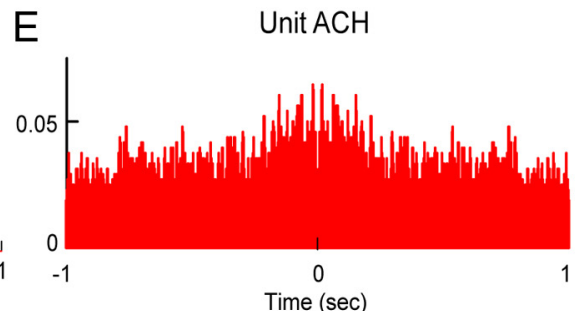

$\mathrm{F}$

Unit-to-EEG STA

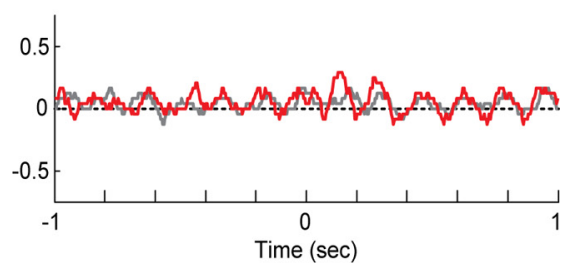

Figure 8. Discharge of glutamatergic PS-max active unit across sleep-wake states. Data from Nb-labeled cell (CBS46U02) that expressed VGluT2 (data not shown) and was located in the LDT (Fig. 2, A0.5). A-C, This VGluT2 ${ }^{+}$cell discharged at its lowest rates during aW (2) $(0.13 \mathrm{~Hz})$ with fast EEG activity and high neck muscle tone, increased its firing during SWS (3) (1.77 Hz) in association with slow EEG activity and low muscle tone and discharged maximally to reach its highest rate during PS (5) $(9.42 \mathrm{~Hz})$ in association with $\theta$ EEG activity and muscle atonia. It increased its rate most markedly immediately preceding PS during tPS (4).D-F, During the state of maximal discharge (PS), the instantaneous firing frequency (200 Hz in the ISIH) was much higher than its average discharge rate and reflected a phasic firing pattern of spike bursts, which was neither rhythmic (in ACH) nor cross-correlated with slow or fast EEG rhythms (in STA). For details and abbreviations, see Figure 4. 


\section{W-max: Nb+/VGluT2+ neuron (\#CBS47U02)}

A
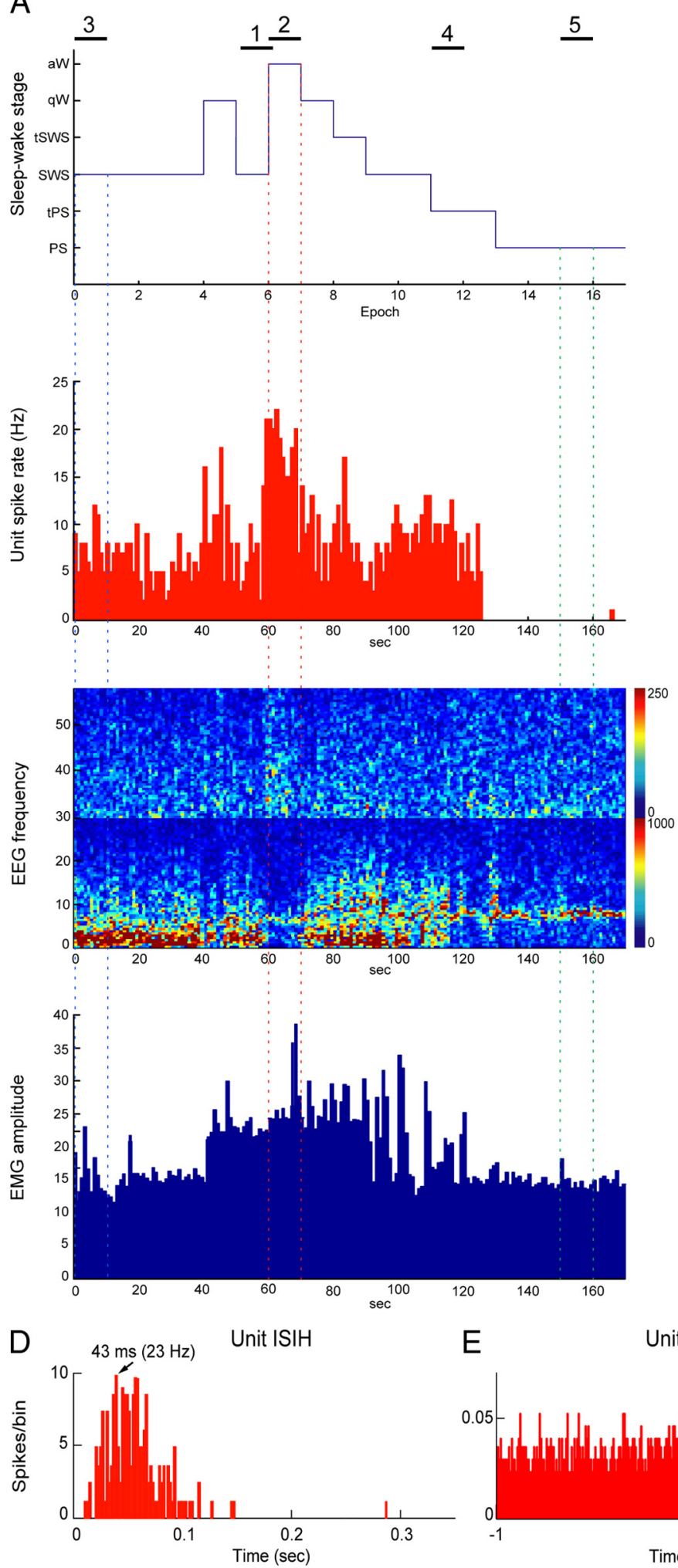

E

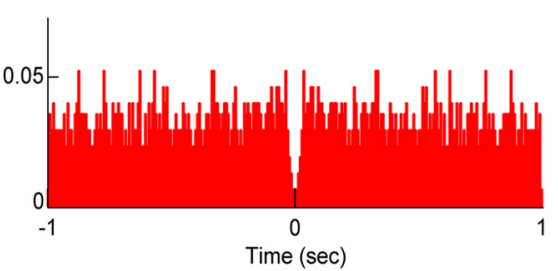

SWS

aW 1 EMG

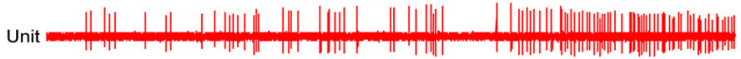

aW

EEG

2 EMG

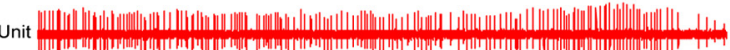
SWS

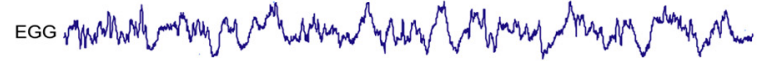

3 EMG

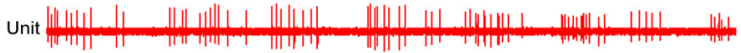

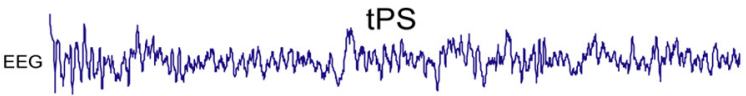

4 EMG

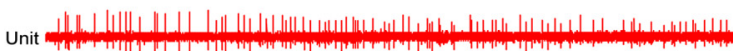

PS

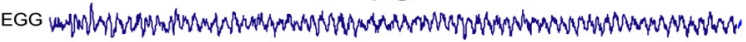
5 EMG

EEG/EMG: $1 \mathrm{mV}$ Unit: $2 \mathrm{mV}$

C

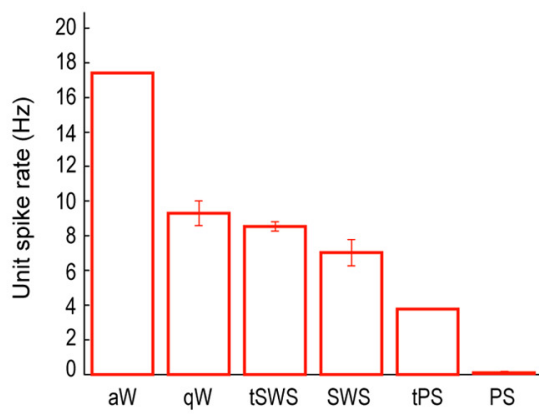

F

Unit-to-EEG STA

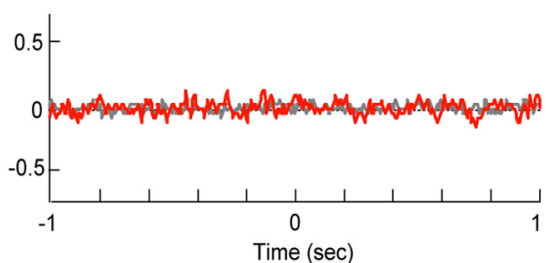

Figure 9. Discharge of glutamatergic W-max active unit across sleep-wake states. Data from Nb-labeled cell (CBS47U02) that expressed VGluT2 (Fig. 1B) and was located in the SubLDT (Fig. 2, A0.5). A-C, This VGluT2 ${ }^{+}$cell discharged maximally and tonically during aW (2) $(17.40 \mathrm{~Hz})$ with fast EEG activity and high neck muscle tone, decreased its firing during SWS (3) $(6.83 \mathrm{~Hz})$ in association with slow EEG activity and low muscle tone, and ceased firing during PS (5) $(0.78 \mathrm{~Hz})$ in association with $\theta \mathrm{EEG}$ activity and muscle atonia. It changed its rate with awakening from SWS (1) and through tPS to become silent during PS (5). The unit discharge was positively correlated with EMG activity $(r=0.69)$. $\boldsymbol{D}-\boldsymbol{F}$, During the state of maximal discharge (aW), the instantaneous firing frequency $(23 \mathrm{~Hz}$ in the ISIH) did not differ much from the average discharge rate, reflecting the tonic regular discharge of the cell, which was neither rhythmic (see ACH) nor cross-correlated with EEG activity (STA). For details and abbreviations, see Figure 4. 


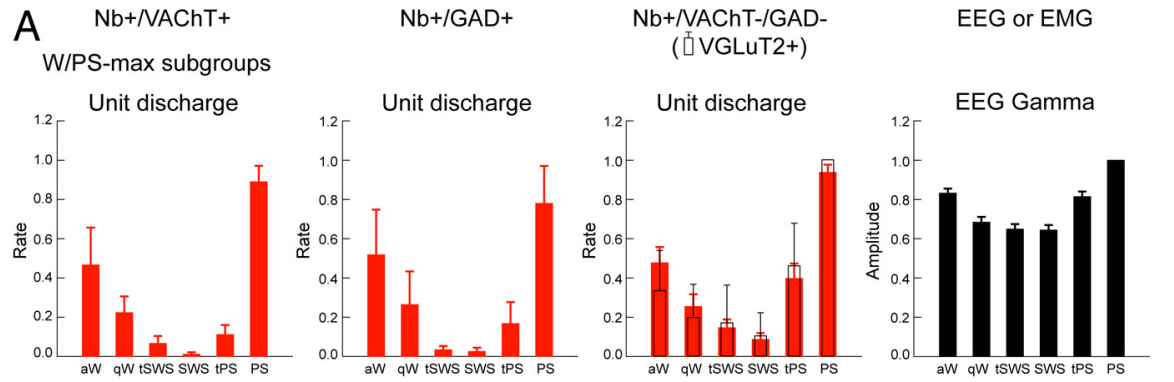

B PS-max subgroups

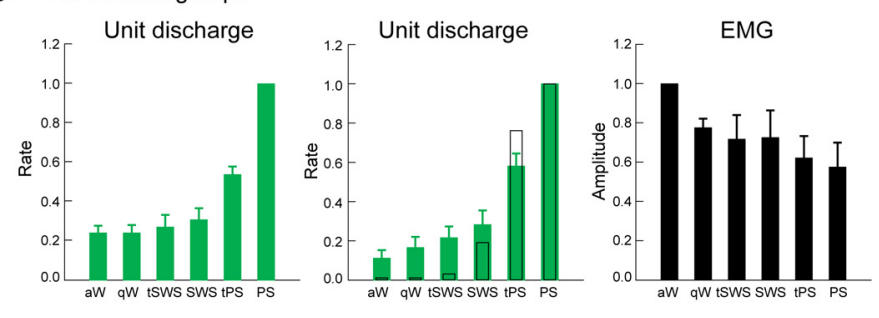

C W-max subgroup

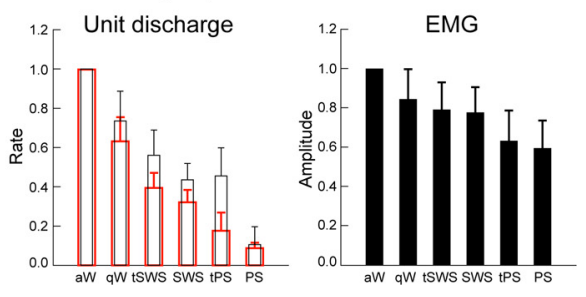

Figure 10. Mean discharge rates of different cell types and subgroups in association with EEG and EMG activity across sleepwake stages. $A$, Discharge rates of cholinergic $\left(\mathrm{Nb}^{+} / \mathrm{VAChT}^{+}, n=6\right), \mathrm{GABAergic}\left(\mathrm{Nb}^{+} / \mathrm{GAD}^{+}, n=5\right)$, and possibly glutamatergic $\left(\mathrm{Nb}^{+} / \mathrm{NAChT}^{-} / \mathrm{GAD}^{-}, n=18\right)$, including a subset of identified glutamatergic (VGluT2 ${ }^{+}, n=3$, black open bars), neurons that discharged maximally during aW and PS in positive correlation with $\gamma$ EEG activity across sleep-wake stages. $\boldsymbol{B}$, Discharge rates of GABAergic $(n=4)$ and possibly glutamatergic $(n=12)$ neurons, including a subset of identified glutamatergic (VGluT2 ${ }^{+}, n=1$, black open bars), neurons that discharged maximally during PS in negative correlation with EMG amplitude across sleep-wake stages. $C$, Discharge rates of possibly glutamatergic $(n=7)$ neurons, including a subset of identified glutamatergic (VGluT2 ${ }^{+}, n=2$, black open bars) neurons that discharged maximally during aW in positive correlation with EMG amplitude across sleep-wake stages. Unit discharge rates were normalized per cell according to individual maximal rate (in W or PS). EEG $\gamma$ and EMG amplitudes were similarly normalized for each cell included.

teristics of histochemically verified cholinergic neurons in anesthetized animals for their identification in unanesthetized animals (Kayama and Ogawa, 1987; el Mansari et al., 1989; Steriade et al., 1990a; Kayama et al., 1992; Koyama et al., 1998; Datta and Siwek, 2002; Sakai, 2012). However, in neither anesthetized (Boucetta and Jones, 2009) nor unanesthetized rats (studied here), did we find that individual neurons could be positively identified as cholinergic, GABAergic, or glutamatergic by their spike or discharge properties, resulting from overlapping variation. Only by histochemical identification of Nb-labeled cells could their neurotransmitter phenotype be determined with certainty, indicating that unidentified neurons that were previously recorded in the region of the LDT or PPT and were presumed to be cholinergic were equally or more likely to have been GABAergic or glutamatergic (Ford et al., 1995; Wang and Morales, 2009; Martinez-Gonzalez et al., 2012).

\section{Role of cholinergic/noncholinergic neurons in cortical activation during $\mathrm{W}$ and $\mathrm{PS}$}

All identified cholinergic neurons in the LDT, SubLDT, and MPPT discharged in association with fast $\gamma$ along with $\theta$ EEG activity, maximally during $\mathrm{W}$ and PS. They virtually ceased firing in association with slow-wave $\delta$ activity during SWS. In their profile, although not their properties, of discharge, the pontomesencephalic cholinergic neurons resemble the basal forebrain cholinergic neurons (Jones, 2004; Lee et al., 2005b). Here, as in the anesthetized rat (Boucetta and Jones, 2009), we found that all the pontomesencephalic cholinergic neurons discharged in a slow $(<10 \mathrm{~Hz})$, single-spike, tonic mode of firing. We do not know whether some cholinergic neurons in the LPPT might discharge in spike bursts to elicit the phasic activity of PS, as suggested by studies of unidentified neurons recorded in vivo in cats (McCarley et al., 1978; Sakai et al., 1990; Steriade et al., 1990b) and in vitro in rats (Ye et al., 2010), although not in vivo in rats (Datta and Siwek, 2002). We conclude from our studies of identified cholinergic neurons that the major influence of LDT/SubLDT and MPPT cholinergic neurons would be through slow, tonic firing and thus primarily upon the tonic activity of $\mathrm{W}$ and PS.

Through ascending projections to the intralaminar and midline thalamic nuclei (Jones and Webster, 1988; Paré et al., 1988) and actions upon excitatory ACh receptors (AChRs), including importantly M1 AChRs (McCormick, 1993), the pontomesencephalic cholinergic neurons can exert a long-lasting excitatory effect upon the nonspecific thalamocortical projection system to stimulate cortical activation during W and PS (Curró Dossi et al., 1991) (Fig. 11). Indeed, the profile of discharge by the cholinergic neurons across sleep-wake states is reflected in the profile of ACh release in the thalamus (Williams et al., 1994). The cholinergic neurons also project along a ventral pathway through which they could activate other neurons of the hypothalamo- and basalocortical relays (Jones and Cuello, 1989; Ford et al., 1995) (Fig. 11). And they project into the brainstem RF (Jones, 1990), where via M1 AChRs (Greene et al., 1989), they could also excite presumed glutamatergic neurons in the $\mathrm{PnO}$ and Mes RF forming the ascending reticular activating system (Steriade, 1981; Jones and Yang, 1985) (Fig. 11).

Also known to give rise to ascending projections into the forebrain (Paré et al., 1988; Jones and Cuello, 1989; Ford et al., 1995), many noncholinergic, including GABAergic and glutamatergic, LDT, SubLDT, and MPPT neurons, discharged like the cholinergic neurons in association with cortical activation, as W/PS-max active neurons (Fig. 11). Unlike the cholinergic neurons, however, the majority of the noncholinergic W/PSmax active neurons were fast spiking $(>14.5 \mathrm{~Hz})$ and would thus likely correspond to similarly fast spiking, W/PS active neurons, which were previously thought to be cholinergic (el Mansari et al., 1989; Steriade et al., 1990a; Datta and Siwek, 2002). These noncholinergic W/PS cells could act upon different target neurons than the cholinergic cells or reinforce the action of ACh upon the same target neurons through faster 


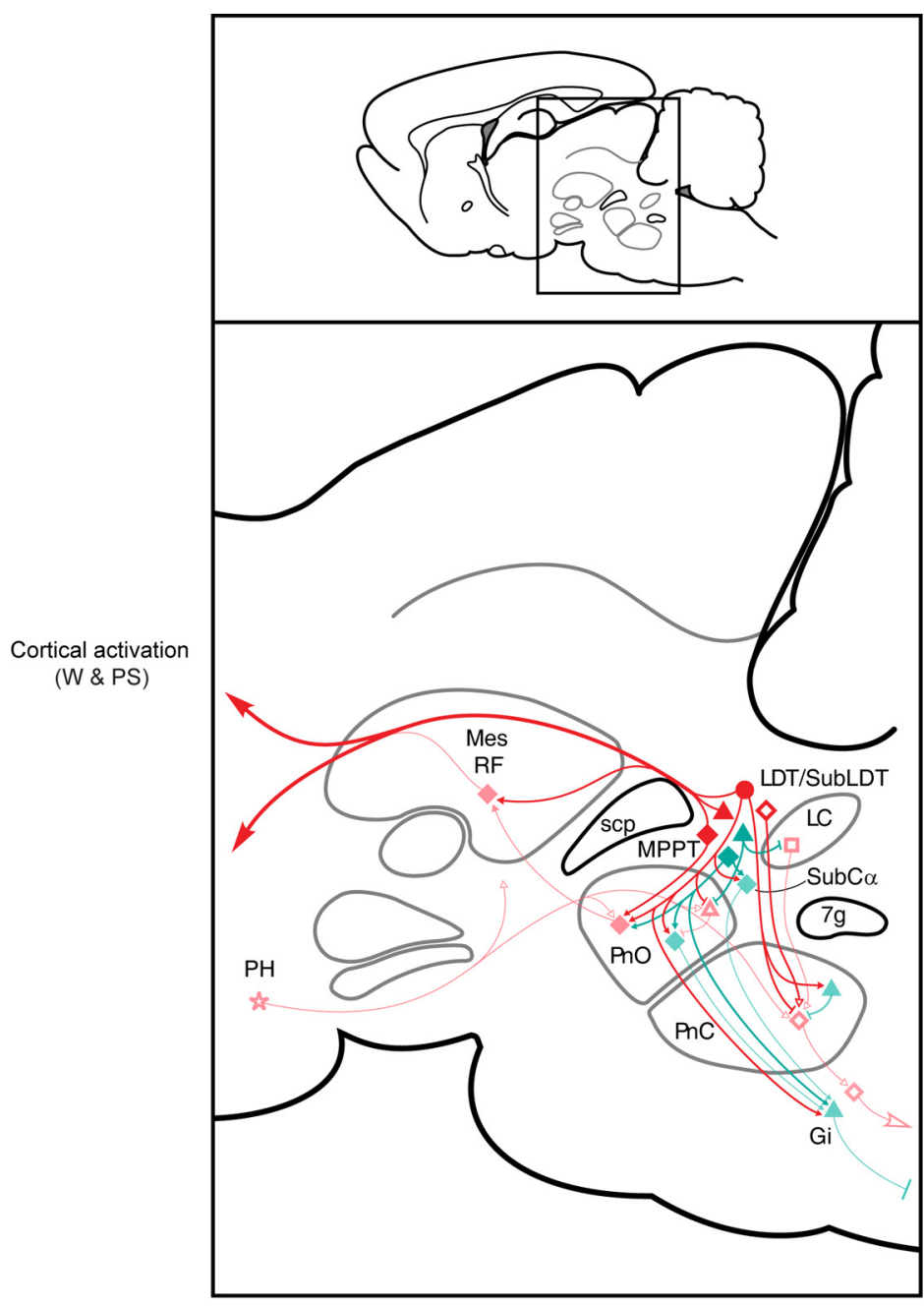

Behavioral wake with muscle tone (W)

Behavioral sleep with muscle atonia

(PS)

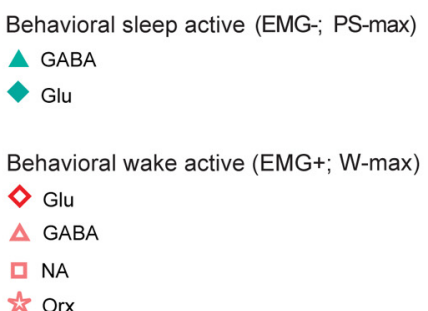

Behavioral sleep active (EMG-; PS-max)

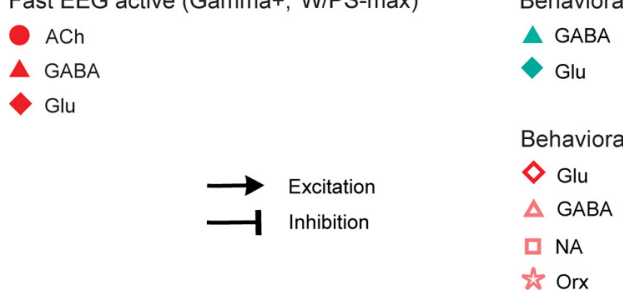

Figure 11. Regulation of sleep-wake states by pontomesencephalic cholinergic/noncholinergic neurons. Sagittal schematic view depicting the recorded and identified functional subtypes of LDT/SubLDT and MPPT cholinergic, GABAergic, and glutamatergic neurons (dark filled symbols) and how they might influence cortical activity and behavior through actions upon other presumed functional subtypes of neurons (light filled symbols) in the brainstem and forebrain. Cholinergic, GABAergic, and glutamatergic LDT/SubLDT and MPPT neurons, which are maximally active during both W and PS (W/PS-max active, filled red symbols) and discharge in positive $(+)$ association with fast EEG $(\gamma)$ activity, could stimulate cortical activation during both W and PS by projections onto presumed glutamatergic neurons located in the Mes and PnO RF (arrows) and/or the thalamus (through a dorsal ascending pathway, large arrow) and hypothalamus and basal forebrain (through a ventral ascending pathway, large arrow). The cholinergic neurons could also promote muscle atonia during PS through excitation of glutamatergic neurons (with M1 AChRs) in the SubC $\alpha$ (arrow) and PnORF (arrow), which are active during PS and project upon GABAergic neurons in the Gi RF. They could also excite GABAergic neurons in the PnC (arrow) and Gi RF (arrow), which are active during PS and can in turn, respectively, inhibit large reticular projection neurons and/or motor neurons in the spinal cord. The cholinergic neurons could conversely inhibit neurons (with M2 AChRs) that are predominantly active during W, including local GABAergic neurons in the Pn0 (bar), which inhibit PS active neurons, and large presumed glutamatergic neurons in the $\mathrm{PnC}$ (bar), which excite motor neurons. The inhibitory actions of ACh would be opposed during W by excitatory influences from noradrenergic locus coeruleus neurons (arrow) and from 0rx neurons (arrows). GABAergic and glutamatergic LDT/SubLDT and MPPT neurons that are maximally active during PS (PS-max active, aqua symbols) in negative (-) association with EMG activity could stimulate behavioral sleep with muscle atonia also by projections into the brainstem. The GABAergic neurons could inhibit their neighboring W active noradrenergic locus coeruleus neurons (bar) and W active GABAergic neurons in the Pn0 (bar). The glutamatergic neurons could stimulate other PS active presumed glutamatergic neurons in the $\mathrm{SubC} \alpha$ (arrow) and $\mathrm{PnO}$ (arrow) and, in parallel with these, stimulate GABAergic (or firing and synaptic actions. Although such cells could be involved in promoting $\gamma$ EEG activity (Simon et al., 2010), they would not appear to drive it because their firing was not crosscorrelated with the high-frequency EEG rhythms in either unanesthetized (here) or anesthetized rats (Boucetta and Jones, 2009).

\section{Role of cholinergic/noncholinergic neurons in PS with muscle atonia}

None of the cholinergic neurons of the LDT, SubLDT, or MPPT discharged selectively during PS or as PS-max active neurons in the current study, in contradiction with previous suppositions (Sakai and Koyama, 1996). Nonetheless, most cholinergic neurons fired at relatively high rates during PS, which is reflected in $\mathrm{ACh}$ release in the pons that is high during PS with atonia and cataplexy in narcoleptic dogs (Reid et al., 1994). And injections of cholinergic agonists into the $\operatorname{SubC} \alpha$ and PnO RF, to which the LDT/PPT neurons project (Jones, 1990; Semba, 1993), elicit PS with muscle atonia (Baghdoyan et al., 1987; for review, see Jones, 1993; Brown et al., 2012).

In the brainstem RF, ACh has both excitatory actions through M1 AChRs and inhibitory actions through M2 AChRs, which might explain its seemingly paradoxical actions on cortical activity and muscle tone with PS (Greene et al., 1989; Brown et al., 2006, 2008; Brischoux et al., 2008; Heister et al., 2009; for review, see Brown et al., 2012). ACh could promote PS through M1 AChR-mediated excitation of neurons in the SubC $\alpha$ and $\mathrm{PnO}$ (Greene et al., 1989; Brown et al., 2006; Heister et al., 2009), which are predominantly active during PS and considered to represent

$\longleftarrow$

glycinergic) neurons located in the Gi RF (arrows) or spinal cord (data not shown) (above). Glutamatergic LDT/SubLDT and MPPT neurons, which are maximally active during W (W-max active, open red symbol) in positive $(+)$ association with EMG activity, could stimulate behavioral arousal with muscle tone during W. They could excite, together with noradrenergic and Orx neurons, the $W$ active presumed glutamatergic neurons in the PnC (above, arrow), that in turn stimulate presumed glutamatergic neurons located in the Gi RF (arrow) or spinal cord (data not shown) (above). $7 \mathrm{~g}$, Genu seventh nerve; Gi, gigantocellular reticular formation; Glu, glutamate; LC, locus coeruleus nucleus; LDT, laterodorsal tegmental nucleus; Mes RF, mesencephalic reticular formation; NA, noradrenaline; $\mathrm{PH}$, posterior hypothalamus; Orx, orexin; $\mathrm{PnC}$, pontine, caudal part RF; Pn0, pontine, oral part RF; PPT, pedunculopontine tegmental nucleus; RF, reticular formation; $s c p$, superior cerebellar peduncle; SubC $\alpha$, subcoeruleus $\alpha$; SubLDT, sublaterodorsal tegmental nucleus. 
PS effector neurons that are glutamatergic (Sakai, 1980; Jones, 1995; Maloney et al., 2000; Lu et al., 2006; Clément et al., 2011) (Fig. 11). ACh could also inhibit through M2 AChRs, GABAergic neurons in the PnO (Brischoux et al., 2008; Brown et al., 2008), which, according to c-Fos expression, are predominantly active during $\mathrm{W}$, when they could hold the adjacent PS effector neurons under inhibition (Xi et al., 1999; Maloney et al., 2000) (Fig. 11). In eliciting muscle atonia, ACh could also directly inhibit through M2 AChRs the large, reticulospinal neurons in the caudal pons $(\mathrm{PnC})$, which are predominantly active during $\mathrm{W}$, or indirectly inhibit them by excitation through M1 AChRs of local GABAergic interneurons, which are predominantly active during PS (Greene et al., 1989; Maloney et al., 2000; Brischoux et al., 2008; Brown et al., 2008) (Fig. 11). Cholinergic LDT/PPT neurons also project to the medullary Gi RF, where they could directly excite GABAergic (Jones et al., 1991) or glycinergic, (Fort et al., 1993) neurons, which project to the spinal cord, are active during PS and could thus effect motor inhibition during PS (Holmes and Jones, 1994; Maloney et al., 2000) (Fig. 11).

The PS-max active neurons recorded here in the LDT, SubLDT, and MPPT were noncholinergic and identified as GABAergic or glutamatergic. They discharged in negative correlation with EMG and could accordingly have an inhibitory influence upon systems promoting behavioral arousal with motor activity and muscle tone. The PS-max GABAergic neurons could inhibit nearby $\mathrm{W}$ active noradrenergic locus coeruleus neurons and GABAergic $\mathrm{PnO}$ neurons to play an important role in gating PS and muscle atonia (Maloney et al., 1999) (Fig. 11). The PS-max active glutamatergic neurons could form part of a larger network of such cells that express c-Fos with PS and include neurons in the SubC $\alpha$ (grouped with those in the SubLDT as the "SLD"; Lu et al., 2006; Clément et al., 2011) and in the PnO (Maloney et al., 2000; Dergacheva et al., 2004). Neurons in these regions project to the Gi RF or spinal cord, where they are presumed to excite other GABAergic (or glycinergic) neurons (above), which could in turn inhibit motoneurons (Fig. 11).

\section{Role of cholinergic/noncholinergic neurons in $\mathrm{W}$ with muscle tone}

None of the pontomesencephalic cholinergic neurons discharged as W selective or max-active neurons. There is however considerable evidence that they promote cortical activation and attention (Inglis et al., 2001), although not necessarily in association with behavioral arousal or movement. Indeed, they have been shown to inhibit the startle reflex during waking through M2 AChRs upon large reticular neurons (Fendt et al., 2001) (Fig. 11). The cholinergic neurons are accordingly more associated with behavioral inhibition and as such stimulating alert waking with relative immobility and even tonic immobility ("feigning death") (Monassi et al., 1997), which is proposed to be similar to narcolepsy with cataplexy (Overeem et al., 2002). These inhibitory actions of the cholinergic neurons could be counterbalanced during $\mathrm{W}$ by excitatory actions of other $\mathrm{W}$-active neurons, including noradrenergic (Takahashi et al., 2010) and orexin neurons (Lee et al., 2005a; Mileykovskiy et al., 2005; Brischoux et al., 2008) (Fig. 11).

$\mathrm{W}$-max active neurons recorded here in the LDT, SubLDT, and MPPT were found to be noncholinergic, nonGABAergic, possibly or identified glutamatergic neurons. They discharged in positive correlation with EMG and could exert an excitatory in- fluence upon reticular neurons, which facilitate motor activity and muscle tone (Fig. 11).

In conclusion, cholinergic, GABAergic, and glutamatergic pontomesencephalic neurons work through different properties and profiles yet in concert to promote cortical activation in association with behavioral arousal and muscle tone or with behavioral immobility and muscle atonia, which underlie W/PS states.

\section{References}

Alonso A, Khateb A, Fort P, Jones BE, Mühlethaler M (1996) Differential oscillatory properties of cholinergic and non-cholinergic nucleus Basalis neurons in guinea pig brain slice. Eur J Neurosci 8:169-182. CrossRef Medline

Armstrong DM, Saper CB, Levey AI, Wainer BH, Terry RD (1983) Distribution of cholinergic neurons in rat brain: demonstrated by the immunocytochemical localization of choline acetyltransferase. J Comp Neurol 216:53-68. CrossRef Medline

Baghdoyan HA, Rodrigo-Angulo ML, McCarley RW, Hobson JA (1987) A neuroanatomical gradient in the pontine tegmentum for the cholinoceptive induction of desynchronized sleep signs. Brain Res 414:245-261. CrossRef Medline

Boucetta S, Jones BE (2009) Activity profiles of cholinergic and intermingled GABAergic and putative glutamatergic neurons in the pontomesencephalic tegmentum of urethane-anesthetized rats. J Neurosci 29:4664-4674. CrossRef Medline

Brischoux F, Mainville L, Jones BE (2008) Muscarinic-2 and orexin-2 receptors on GABAergic and other neurons in the rat mesopontine tegmentum and their potential role in sleep-wake state control. J Comp Neurol 510: 607-630. CrossRef Medline

Brown RE, Winston S, Basheer R, Thakkar MM, McCarley RW (2006) Electrophysiological characterization of neurons in the dorsolateral pontine rapid-eye-movement sleep induction zone of the rat: intrinsic membrane properties and responses to carbachol and orexins. Neuroscience 143: 739-755. CrossRef Medline

Brown RE, McKenna JT, Winston S, Basheer R, Yanagawa Y, Thakkar MM, McCarley RW (2008) Characterization of GABAergic neurons in rapideye-movement sleep controlling regions of the brainstem reticular formation in GAD67-green fluorescent protein knock-in mice. Eur J Neurosci 27:352-363. CrossRef Medline

Brown RE, Basheer R, McKenna JT, Strecker RE, McCarley RW (2012) Control of sleep and wakefulness. Physiol Rev 92:1087-1187. CrossRef Medline

Clément O, Sapin E, Bérod A, Fort P, Luppi PH (2011) Evidence that neurons of the sublaterodorsal tegmental nucleus triggering paradoxical (REM) sleep are glutamatergic. Sleep 34:419-423. Medline

Curró Dossi R, Paré D, Steriade M (1991) Short-lasting nicotinic and longlasting muscarinic depolarizing responses of thalamocortical neurons to stimulation of mesopontine cholinergic nuclei. J Neurophysiol 65:393406. Medline

Datta S, Siwek DF (2002) Single cell activity patterns of pedunculopontine tegmentum neurons across the sleep-wake cycle in the freely moving rats. J Neurosci Res 70:611-621. CrossRef Medline

Dergacheva OY, Khachikova IE, Burikov AA (2004) Dynamics of neuron spike activity in the oral nucleus of the pons during the sleep-waking cycle in cats. Neurosci Behav Physiol 34:485-489. CrossRef Medline

el Mansari M, Sakai K, Jouvet M (1989) Unitary characteristics of presumptive cholinergic tegmental neurons during the sleep-waking cycle in freely moving cats. Exp Brain Res 76:519-529. CrossRef Medline

Fendt M, Li L, Yeomans JS (2001) Brain stem circuits mediating prepulse inhibition of the startle reflex. Psychopharmacology (Berl) 156:216-224. CrossRef Medline

Ford B, Holmes CJ, Mainville L, Jones BE (1995) GABAergic neurons in the rat pontomesencephalic tegmentum: codistribution with cholinergic and other tegmental neurons projecting to the posterior lateral hypothalamus. J Comp Neurol 363:177-196. CrossRef Medline

Fort P, Luppi PH, Jouvet M (1993) Glycine-immunoreactive neurones in the cat brain stem reticular formation. Neuroreport 4:1123-1126. Medline

Greene RW, Gerber U, McCarley RW (1989) Cholinergic activation of medial pontine reticular formation neurons in vitro. Brain Res 476:154-159. CrossRef Medline 
Hassani OK, Lee MG, Henny P, Jones BE (2009) Discharge profiles of identified GABAergic in comparison to cholinergic and putative glutamatergic basal forebrain neurons across the sleep-wake cycle. J Neurosci 29: 11828-11840. CrossRef Medline

Heister DS, Hayar A, Garcia-Rill E (2009) Cholinergic modulation of GABAergic and glutamatergic transmission in the dorsal subcoeruleus: mechanisms for REM sleep control. Sleep 32:1135-1147. Medline

Holmes CJ, Jones BE (1994) Importance of cholinergic, GABAergic, serotonergic and other neurons in the medullary reticular formation for sleep-wake states studied by cytotoxic lesions in the cat. Neuroscience 62:1179-1200. CrossRef Medline

Inglis WL, Olmstead MC, Robbins TW (2001) Selective deficits in attentional performance on the 5-choice serial reaction time task following pedunculopontine tegmental nucleus lesions. Behav Brain Res 123:117131. CrossRef Medline

Jones BE (1990) Immunohistochemical study of choline acetyl transferaseimmunoreactive processes and cells innervating the pontomedullary reticular formation. J Comp Neurol 295:485-514. CrossRef Medline

Jones BE (1993) The organization of central cholinergic systems and their functional importance in sleep-waking states. Prog Brain Res 98:61-71. CrossRef Medline

Jones BE (1995) Reticular formation: cytoarchitecture, transmitters and projections. In: The rat nervous system, Ed 2 (Paxinos G, ed), pp 155-171. Sydney: Academic Australia.

Jones BE (2004) Activity, modulation and role of basal forebrain cholinergic neurons innervating the cerebral cortex. Prog Brain Res 145:157-169. CrossRef Medline

Jones BE, Cuello AC (1989) Afferents to the basal forebrain cholinergic cell area from pontomesencephalic-catecholamine, serotonin, and acetylcholine-neurons. Neuroscience 31:37-61. CrossRef Medline

Jones BE, Webster HH (1988) Neurotoxic lesions of the dorsolateral pontomesencephalic tegmentum-cholinergic cell area in the cat. I. Effects upon the cholinergic innervation of the brain. Brain Res 451:13-32. CrossRef Medline

Jones BE, Yang TZ (1985) The efferent projections from the reticular formation and the locus coeruleus studied by anterograde and retrograde axonal transport in the rat. J Comp Neurol 242:56-92. CrossRef Medline

Jones BE, Holmes CJ, Rodriguez-Veiga E, Mainville L (1991) GABAsynthesizing neurons in the medulla: their relationship to serotonincontaining and spinally projecting neurons in the rat. J Comp Neurol 313:349-367. CrossRef Medline

Kayama Y, Ogawa T (1987) Electrophysiology of ascending, possibly cholinergic neurons in the rat laterodorsal tegmental nucleus: comparison with monoamine neurons. Neurosci Lett 77:277-282. CrossRef Medline

Kayama Y, Ohta M, Jodo E (1992) Firing of "possibly" cholinergic neurons in the rat laterodorsal tegmental nucleus during sleep and wakefulness. Brain Res 569:210-220. CrossRef Medline

Koyama Y, Honda T, Kusakabe M, Kayama Y, Sugiura Y (1998) In vivo electrophysiological distinction of histochemically identified cholinergic neurons using extracellular recording and labelling in rat laterodorsal tegmental nucleus. Neuroscience 83:1105-1112. CrossRef Medline

Lee MG, Manns ID, Alonso A, Jones BE (2004) Sleep-wake related discharge properties of basal forebrain neurons recorded with micropipettes in head-fixed rats. J Neurophysiol 92:1182-1198. CrossRef Medline

Lee MG, Hassani OK, Jones BE (2005a) Discharge of identified orexin/ hypocretin neurons across the sleep-waking cycle. J Neurosci 25:67166720. CrossRef Medline

Lee MG, Hassani OK, Alonso A, Jones BE (2005b) Cholinergic basal forebrain neurons burst with $\theta$ during waking and paradoxical sleep. J Neurosci 25:4365-4369. CrossRef Medline

Lu J, Sherman D, Devor M, Saper CB (2006) A putative flip-flop switch for control of REM sleep. Nature 441:589-594. CrossRef Medline

Maloney KJ, Cape EG, Gotman J, Jones BE (1997) High-frequency $\gamma$ electroencephalogram activity in association with sleep-wake states and spontaneous behaviors in the rat. Neuroscience 76:541-555. CrossRef Medline

Maloney KJ, Mainville L, Jones BE (1999) Differential c-Fos expression in cholinergic, monoaminergic and GABAergic cell groups of the pontomesencephalic tegmentum after paradoxical sleep deprivation and recovery. J Neurosci 19:3057-3072. Medline

Maloney KJ, Mainville L, Jones BE (2000) c-Fos expression in GABAergic, serotonergic and other neurons of the pontomedullary reticular forma- tion and raphe after paradoxical sleep deprivation and recovery. J Neurosci 20:4669-4679. Medline

Manns ID, Alonso A, Jones BE (2000) Discharge properties of juxtacellularly labeled and immunohistochemically identified cholinergic basal forebrain neurons recorded in association with the electroencephalogram in anesthetized rats. J Neurosci 20:1505-1518. Medline

Martinez-Gonzalez C, Wang HL, Micklem BR, Bolam JP, Mena-Segovia J (2012) Subpopulations of cholinergic, GABAergic, and glutamatergic neurons in the pedunculopontine nucleus contain calcium-binding proteins and are heterogeneously distributed. Eur J Neurosci 35:723-734. CrossRef Medline

McCarley RW, Nelson JP, Hobson JA (1978) Ponto-geniculo-occipital (PGO) burst neurons: correlative evidence for neuronal generators of PGO waves. Science 201:269-272. CrossRef Medline

McCormick DA (1993) Actions of acetylcholine in the cerebral cortex and thalamus and implications for function. Prog Brain Res 98:303-308. CrossRef Medline

Mileykovskiy BY, Kiyashchenko LI, Siegel JM (2005) Behavioral correlates of activity in identified hypocretin/orexin neurons. Neuron 46:787-798. CrossRef Medline

Monassi CR, Hoffmann A, Menescal-de-Oliveira L (1997) Involvement of the cholinergic system and periaqueductal gray matter in the modulation of tonic immobility in the guinea pig. Physiol Behav 62:53-59. CrossRef Medline

Overeem S, Lammers GJ, van Dijk JG (2002) Cataplexy: 'tonic immobility' rather than 'REM-sleep atonia?' Sleep Med 3:471-477. Medline

Paré D, Smith Y, Parent A, Steriade M (1988) Projections of brainstem core cholinergic and non-cholinergic neurons of cat to intralaminar and reticular thalamic nuclei. Neuroscience 25:69-86. CrossRef Medline

Paxinos G, Watson C (1986) The rat brain in stereotaxic coordinates. Sydney: Academic.

Reid MS, Siegel JM, Dement WC, Mignot E (1994) Cholinergic mechanisms in canine narcolepsy: II. Acetylcholine release in the pontine reticular formation is enhanced during cataplexy. Neuroscience 59:523-530. CrossRef Medline

Rye DB, Saper CB, Lee HJ, Wainer BH (1987) Pedunculopontine tegmental nucleus of the rat: cytoarchitecture, cytochemistry, and some extrapyramidal connections of the mesopontine tegmentum. J Comp Neurol 259: 483-528. CrossRef Medline

Sakai K (1980) Some anatomical and physiological properties of pontomesencephalic tegmental neurons with special reference to the PGO waves and postural atonia during paradoxical sleep in the cat. In: The reticular formation revisited (Hobson JA, Brazier MAB, eds), pp 427-447. New York: Raven.

Sakai K (2012) Discharge properties of presumed cholinergic and noncholinergic laterodorsal tegmental neurons related to cortical activation in non-anesthetized mice. Neuroscience 224:172-190. CrossRef Medline

Sakai K, Koyama Y (1996) Are there cholinergic and non-cholinergic paradoxical sleep-on neurones in the pons? Neuroreport 7:2449-2453. CrossRef Medline

Sakai K, el Mansari M, Jouvet M (1990) Inhibition by carbachol microinjections of presumptive cholinergic PGO-on neurons in freely moving cats. Brain Res 527:213-223. CrossRef Medline

Semba K (1993) Aminergic and cholinergic afferents to REM sleep induction regions of the pontine reticular formation in the rat. J Comp Neurol 330:543-556. CrossRef Medline

Semba K, Reiner PB, Fibiger HC (1990) Single cholinergic mesopontine tegmental neurons project to both the pontine reticular formation and the thalamus in the rat. Neuroscience 38:643-654. CrossRef Medline

Simon C, Kezunovic N, Ye M, Hyde J, Hayar A, Williams DK, Garcia-Rill E (2010) $\gamma$ band unit activity and population responses in the pedunculopontine nucleus. J Neurophysiol 104:463-474. CrossRef Medline

Steriade M (1981) Mechanisms underlying cortical activation: neuronal organization and properties of the midbrain reticular core and intralaminar thalamic nuclei. In: Brain mechanisms and perceptual awareness (Pompeiano O, Ajmone Marsan C, eds), pp 327-377. New York: Raven.

Steriade M (2004) Acetylcholine systems and rhythmic activities during the waking-sleep cycle. Prog Brain Res 145:179-196. CrossRef Medline

Steriade M, Datta S, Paré D, Oakson G, Curró Dossi RC (1990a) Neuronal activities in brain-stem cholinergic nuclei related to tonic activa- 
tion processes in thalamocortical systems. J Neurosci 10:2541-2559. Medline

Steriade M, Paré D, Datta S, Oakson G, Curró Dossi R (1990b) Different cellular types in mesopontine cholinergic nuclei related to pontogeniculo-occipital waves. J Neurosci 10:2560-2579. Medline

Swanson L (1992) Brain maps: structure of the rat brain. Amsterdam: Elsevier.

Takahashi K, Kayama Y, Lin JS, Sakai K (2010) Locus coeruleus neuronal activity during the sleep-waking cycle in mice. Neuroscience 169:11151126. CrossRef Medline

Wang HL, Morales M (2009) Pedunculopontine and laterodorsal tegmental nuclei contain distinct populations of cholinergic, glutamatergic and GABAergic neurons in the rat. Eur J Neurosci 29:340-358. CrossRef Medline
Webster HH, Jones BE (1988) Neurotoxic lesions of the dorsolateral pontomesencephalic tegmentum-cholinergic cell area in the cat: II. Effects upon sleep-waking states. Brain Res 458:285-302. CrossRef Medline

Williams JA, Comisarow J, Day J, Fibiger HC, Reiner PB (1994) Statedependent release of acetylcholine in rat thalamus measured by in vivo microdialysis. J Neurosci 14:5236-5242. Medline

Xi MC, Morales FR, Chase MH (1999) Evidence that wakefulness and REM sleep are controlled by a GABAergic pontine mechanism. J Neurophysiol 82:2015-2019. Medline

Ye M, Hayar A, Strotman B, Garcia-Rill E (2010) Cholinergic modulation of fast inhibitory and excitatory transmission to pedunculopontine thalamic projecting neurons. J Neurophysiol 103:2417-2432. CrossRef Medline 